\title{
Analysis of dynamic and fatigue effects in an old metallic riveted bridge
}

\author{
Fernando Marques *, Carlos Moutinho, Filipe Magalhães, Elsa Caetano, Álvaro Cunha \\ Faculty of Engineering of the University of Porto (FEUP), R. Dr. Roberto Frias, 4200-465 Porto, Portugal
}

\section{A R T I C L E I N F O}

\section{Article history:}

Received 17 October 2013

Accepted 3 April 2014

Available online $\mathrm{xxxx}$

\section{Keywords:}

Railway bridges

Dynamic analysis

Fatigue assessment

Monitoring

Experimental tests

\begin{abstract}
A B S T R A C T
The fatigue behaviour of steel railway bridges is a complex phenomenon. On the one side, the Engineer must face the problem of dynamic amplification of the loads and their randomness, on the other side, the fatigue resistance is highly dependent on the load itself, since for different stress levels the material can sustain different number of cycles. This complexity makes the identification of the critical elements for structural safety a difficult task. In this context, and in the framework of the European research project FADLESS, the Laboratory of Vibrations and Monitoring (ViBest) of FEUP has conducted extensive research concerning the evaluation of dynamic effects and fatigue analysis of an old riveted railway bridge. Owing to the importance of this phenomenon, complementary numerical and experimental approaches have been used to assess fatigue effects. This article describes the main steps taken towards the goal of evaluating the dynamic behaviour and the fatigue life of this structure.
\end{abstract}

(c) 2014 Elsevier Ltd. All rights reserved.

\section{Introduction}

Historically, the economic development has been always associated with the construction of railway lines, or with subsequent increase of traffic, vehicle axle loads and speed. Therefore, old railway metallic bridges, in many cases with more than one hundred years, have been required over the years to carry heavier vehicles and endure higher velocities than allowed by the original design. In addition, the cumulated degradation due to corrosion and fatigue contributes to an increased concern for their safety [1].

Owing to economic, cultural and environmental reasons, replacing every bridge at the end of the original design life has not proved to be sustainable. Additionally, society increasingly requires an optimised use of resources balanced with a deep sense of cultural and patrimonial preservation. This means that many structures, and particularly railway bridges, are considered historic landmarks and must therefore be preserved. These considerations make it clear that it is very important to correctly determine the structural behaviour of these structures, thereby making use of the latest scientific knowledge, in order to assess their fitness for further use.

In this context, since it is responsible for $80 \%$ to $90 \%$ of failures in steel structures [2], fatigue has emerged as one of the major concerns associated with old metallic railway bridges. Fisher et al. [3,4] showed that the majority of fatigue cracks are caused by distortion of member cross sections, local vibration and out-of-plane bending of webs.

\footnotetext{
* Corresponding author.

E-mail address: dec11014@fe.up.pt (F. Marques).

URL: http://www.fe.up.pt/vibest (F. Marques).
}

Numerical approaches, using local finite element models, nowadays allow one to study the realistic behaviour of structures of this kind with appropriate consideration of vibration-induced distortion and fatigue [5].

Furthermore, the evaluation of such phenomenon benefits from the implementation of monitoring campaigns, since they reduce the uncertainties associated with the variables of the problem [6]. For instance, in [7], the use of continuous dynamic monitoring made possible to detect damage by evaluating the variation of modal parameters as a function of time after appropriate removal of effects of environmental and operational factors. Particularly in the domain of railway bridges, Reference [8] presents a case where monitoring was used successfully for strain and acceleration measurements leading to the enhanced fatigue assessment of a steel bridge in Sweden.

In this context, the Laboratory of Vibrations and Structural Monitoring (ViBest) of FEUP has developed an extensive research concerning the evaluation of dynamic effects and fatigue analysis of the Portuguese metallic railway bridge of Trezói. In particular, strain measurement campaigns were conducted to evaluate the stress patterns in the main structural elements and stresses in the critical details for fatigue analysis, with the final goal of adding a contribution to the understanding of localised fatigue vibration effects.

This paper describes the experimental and numerical studies developed and presents the results achieved with MatLab routines developed to process the data. Preliminary studies included the development of an ambient vibration test and a global fatigue assessment using a beam FEM that was "tuned" to fit the identified bridge dynamic properties. This provided crucial information for the construction of more detailed local FEM models, as well as for the design of the continuous dynamic 
monitoring system. Subsequently, dynamic analyses were conducted using real train characteristics to understand the importance of local modes in the fatigue calculations. Finally, the results obtained from the field measurement campaigns were used to calculate a more accurate fatigue residual life of this bridge.

\section{Description of the bridge}

The Trezói Bridge (Fig. 1) is located in the international "Beira Alta" route that links Portugal to Spain, at the km 62 north of Mortágua in the village of Trezói. The bridge was constructed as part of a project to replace existing bridges in the "Beira Alta" route, carried out during the decade of 50, and was opened to traffic in August 1956. The project was funded by the Marshall Plan, and the conception, manufacture and mounting, together with 6 other bridges of larger span of the same line, was of the responsibility of the German House Fried Krupp.

This steel riveted bridge has three spans; their lengths are $48 \mathrm{~m}$ for the central span and $39 \mathrm{~m}$ for the other two. The total length of the bridge is $126 \mathrm{~m}$. The two inverted Warren truss girders that constitute the metallic deck of the bridge are $5.68 \mathrm{~m}$ in height. The girder panels are $6.50 \mathrm{~m}$ wide in the central span and $6.00 \mathrm{~m}$ in the end spans. Two trapezoidal shape trusses acting as columns and two granite masonry abutments transmit the loads carried by the structure to the foundation. The bridge has a constant width of $4.40 \mathrm{~m}$ throughout its length.

The cross girders, as well as the stringers resting on them, were built using "I-shaped" sections. The cross girders are $71 \mathrm{~cm}$ in height and are connected to the lateral vertical elements with riveted plates as shown in Fig. 3. The chords and diagonals of the truss girders are formed by double "U-shape" sections.

The bearing supports of the superstructure are metallic and allow free rotations in the structure plane. At the east support the longitudinal displacements are constrained, while at the west support deformations caused by longitudinal horizontal forces (thermal actions, braking, etc.) are allowed.

The stringers are aligned with the rails which is a fortunate conception option since a misaligned rail normally induces secondary stresses in the web of the stringers.

\section{Numerical modelling of the dynamic behaviour}

\subsection{Numerical modelling of the global dynamic behaviour}

A first numerical study was conducted based on a simple FE model using the software SOLVIA [9] to evaluate the dynamic behaviour of the bridge using a discretisation of the structure in 3D beam and truss elements (Fig. 4). Due to the relatively low computational effort required by this model, it was possible to make a first calculation of natural frequencies and modal shapes, and to run simulations of train crossing, introducing also the train-bridge interaction effect, and using the resulting nominal stresses to obtain a preliminary fatigue assessment.

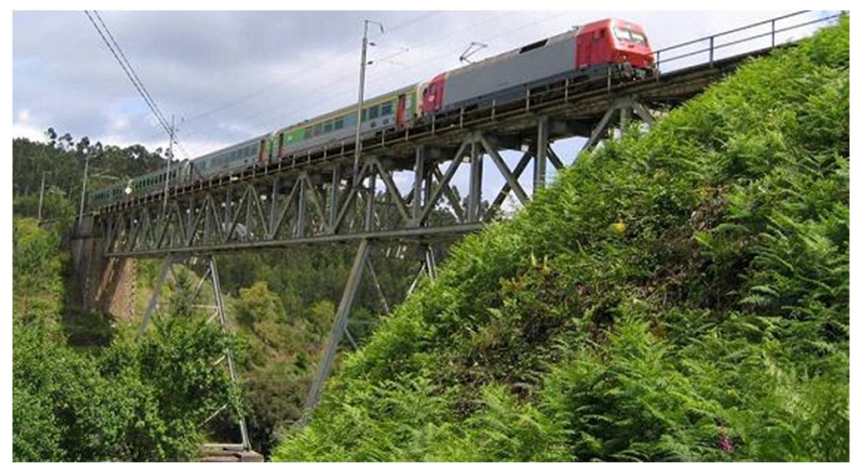

Fig. 1. The Trezói bridge.
The deck and the lateral exterior elements of the columns were simulated with beam elements, while truss elements were used to represent the inner members that form a triangular geometry of the columns. The connection of these columns to the bridge deck is hinged, since there are mechanical devices that allow free rotation in the vertical longitudinal plane of the bridge. Several point masses were distributed along the deck and the columns to simulate the metallic connections, rivets and wood sleepers. The same elasticity modulus of $200 \mathrm{GPa}$ was adopted for the deck and for the columns.

The bearings of the deck at the abutments allow the rotation in the vertical plane. Longitudinal movement is allowed in the east bearing and constrained in the west bearing. However, for low levels of excitation, as is the case during ambient vibration tests, the behaviour of these supports can be different, since friction forces can prevent displacements or rotations. As a consequence, for comparison with the frequencies and modal configurations obtained experimentally, restraining of the longitudinal displacements in both supports was introduced.

Due to localised vibration effects detected in these analyses, more detailed models were further developed.

\subsection{Numerical modelling of local dynamic behaviour}

The finite element model developed in the previous stage using beam elements was subsequently enhanced in order to capture local vibration modes that are not captured by the beam FEM. In Fig. 5 the mesh of this new model is schematically represented. As observed in this figure, the cross-girder above the column, the two adjacent cross-girders, the stringers, diagonals, top and bottom chords and vertical elements that are connected with the vertical column are simulated with 4noded shell elements. The contact and friction between the individual parts of the connections as well as the rivets were not taken into account. The same modelling was made for the structural elements connected to the extremity supports. The rails and sleepers were not simulated and the corresponding masses were idealized as point masses located at the centre of gravity of these elements.

In these two regions, all secondary elements were conveniently discretised in order to characterise the real behaviour of these structural details. A special attention was given to the joints of the cross girders in order to capture local vibration modes, the effect of secondary bending moments and eventual distortion. The stringers that support the rails were also discretised with shell elements, so that the connection between the flange of these elements and the flange of the cross girders was correctly modelled in order to capture distortion effects.

"Rigid links" were introduced between the nodes connecting the bar elements with the corresponding shell elements that constitute the top and bottom chords, to simulate accurately the continuity between structural joints.

This model was also calibrated using the results from the initial ambient vibration test. The global vibration modes were compared and some slight modifications were made in terms of mass distribution and boundary conditions in order to achieve greater agreement between the calculated and identified modal shapes and frequencies.

With this model it was thus possible to calculate stresses that are enhanced due to geometric effects.

\subsection{Evaluation of traffic induced effects}

Numerical simulations were conducted in order to evaluate the structural response due to trains crossing. The calculations made, including the interaction effect between the bridge and the train, led to the conclusion that for this specific structure the effects due to the inertia of the vehicle are much inferior to the effects of its weight. In this case, the phenomenon of energy transfer between the bridge and the suspension of the vehicles showed to be of negligible importance for the range of circulation velocities that are possible and allowed in this bridge. To reach those conclusions, two methodologies were 


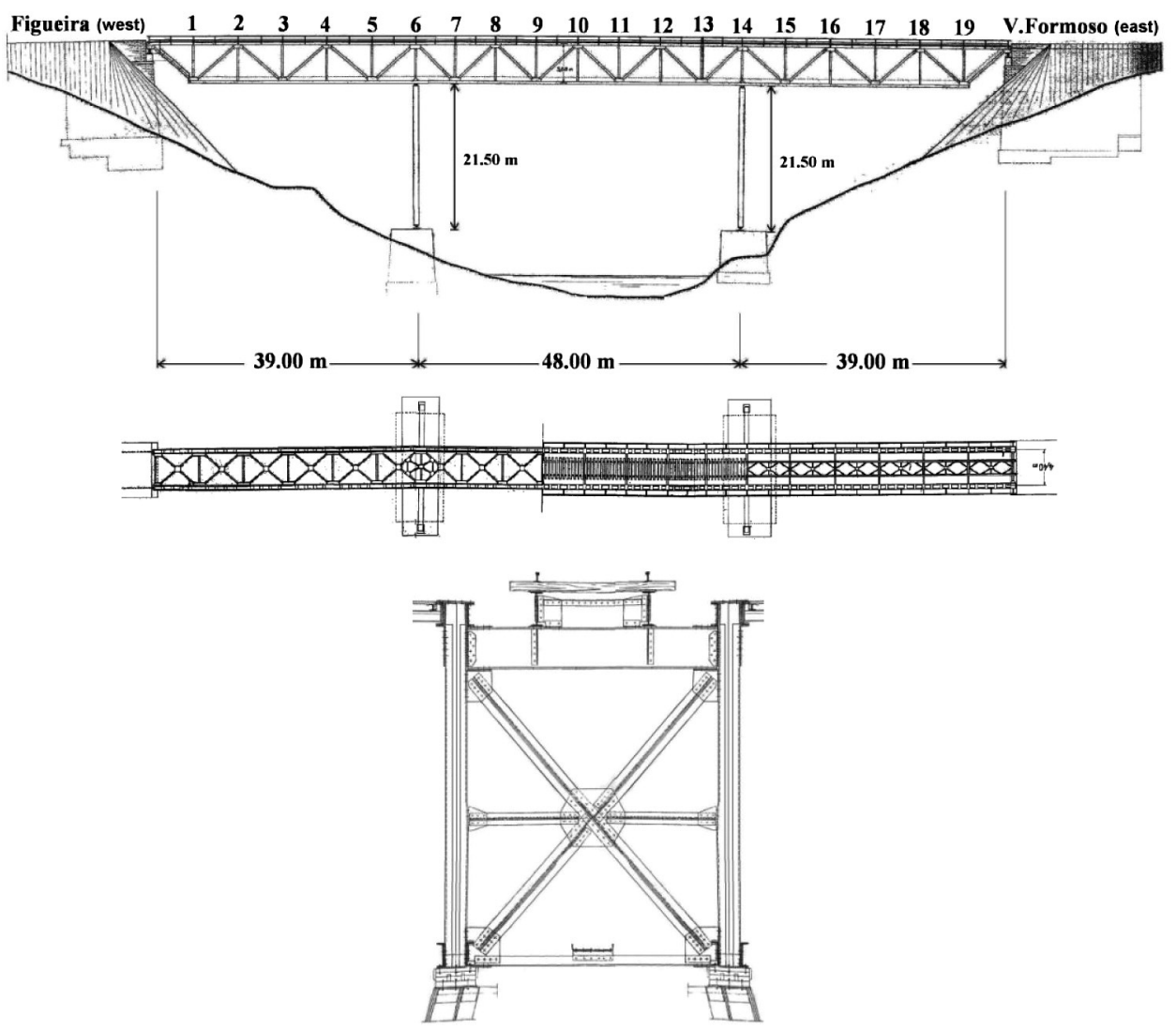

Fig. 2. Elevation, plan view and cross section of the Trezói bridge.

implemented within the dynamic calculations: the moving load methodology, which allows a fast and reliable way to obtain dynamic stresses and deformations; and a methodology that uses contact surfaces to simulate not only the dynamic behaviour of the bridge, but also its interaction with the train structure and mass.

The first methodology consists in varying the vertical forces applied to the nodes belonging to the stringers, creating a set of punctual loads that simulate the space variation of the load through a time variation of its value. Since the load is applied directly to the stringers, the beneficial effect of load distribution due to the rails and sleepers is neglected. In this case, a modal analysis was made and a time step of $\Delta t=0.001 \mathrm{~s}$ allowed a correct description of modes with frequencies up to $125 \mathrm{~Hz}$. To include the interaction effect, the train was modelled as an independent structure that interacts with the bridge. This was achieved using a specific algorithm included in SOLVIA software [9] which allows the use of contact surfaces. This algorithm is described in detail in Bathe [10]. For this dynamic contact analysis, direct integration was used with the Newmark time integration method and a time step of $\Delta t=0.0001 \mathrm{~s}$. In both analyses the stringers were discretised with a length of $0.60 \mathrm{~m}$.
Taking into account the conclusions of these previous studies, the calculations presented in the next sections were made using the less time consuming methodology of the moving load technique.

\section{Experimental assessment of the dynamic behaviour and Fe model validation}

\subsection{Identification of modal properties based on an ambient vibration test}

Taking into account the important role that output-only dynamic testing of bridges plays in the assessment of the dynamic structural behaviour $[11,12]$, an ambient vibration test was conducted with the purpose of adjusting and validating the numerical finite element model. The adjustment was made modifying when necessary the model's mechanical characteristics, the distribution of mass and the support conditions.

Seismographs fitted with triaxial accelerometers were chosen for the field measurements because they appeared to be the most adequate, since these units are completely independent between them and of any external source, they possess internal batteries, the collected information
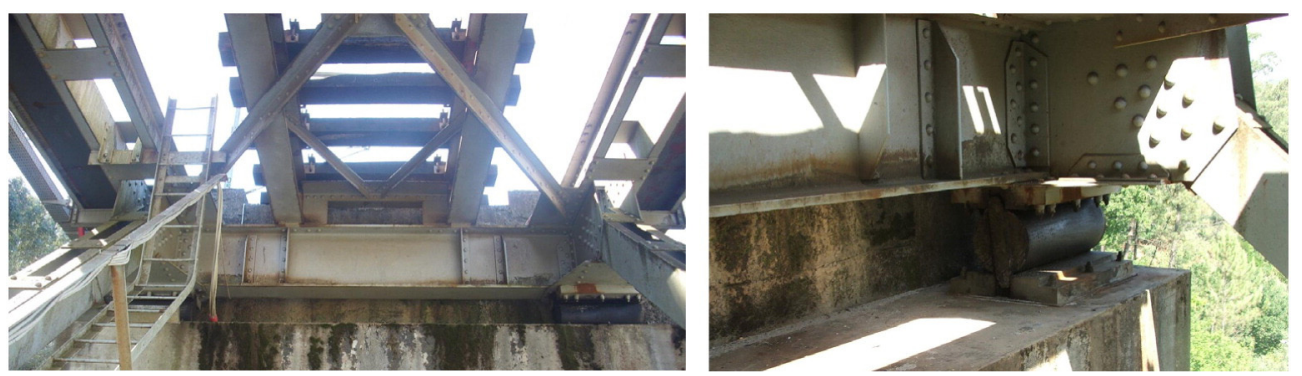

Fig. 3. Local view of the cross-girder at the end support. 


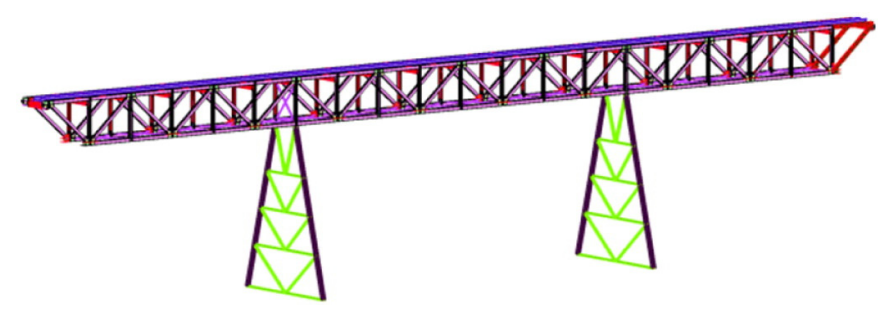

Fig. 4. Global view of the mesh of the 3D beam finite element model.

is kept in an internal memory card and their synchronisation is assured by GPS, thus eliminating the necessity of electric cables.

Accelerations due to ambient excitation were measured according to three orthogonal directions at 19 sections at the top of one of the main beams (Fig. 2). In each setup of $12 \mathrm{~min}$, a seismograph was placed at a reference point located $6 \mathrm{~m}$ apart from the middle of the central span in a location where the majority of the modal coordinates would be different from zero, and two others were placed successively at the 18 remaining points of measurement. For the identification of torsion modes, the ambient response was measured simultaneously at both edges of one section (upstream and downstream).

With the time series obtained in each setup, average normalised power spectra (ANSPD) for the vertical and transversal directions were calculated (Fig. 6). The selection of peaks of these spectra permitted the identification of the natural frequencies of the structure in the frequency range of interest.

Figs. 7 to 9 present a comparison between identified and calculated mode shapes related to the most relevant natural frequencies. It's worth noting that the modes identified experimentally show that the deck does not undergo longitudinal movements. Therefore, the hypothesis of fixing longitudinal movements in the abutments is correct.

Table 1 summarises the frequencies and modal configurations identified by the Peak Picking method. These results are compared with the values obtained from the finite element model.

From the analysis of Table 1 and of Figs. 7 to 9, it can be concluded that the correlation between identified and calculated natural frequencies is very good.

It is stressed that the experimental results above described were subsequently confirmed with an advanced frequency-domain operational modal analysis that is able to deal with uncertainties [13]. In this reference the starting point is the PolyMAX method, and then an iterative maximum likelihood estimation method is introduced as an extension to PolyMAX, whose main benefit is more evident in case of noisy data. Based on this PolyMAX-Plus algorithm, natural frequencies, deck mode shapes and modal damping ratios were computed and are presented in Fig. 10.
The similarity between the results obtained with the Peak-Picking method and with this new methodology is evident. This fact increases the confidence in the values estimated for the natural frequencies and mode shapes.

\subsection{Identification of natural frequencies of local vibration modes of cross-girders}

According to the fatigue analysis described in Section 5, the crossgirders are the structural elements that can be more affected by fatigue damage, which can depend in a significant extent from the excitation of local vibration modes. Therefore, in order to preliminary estimate dominant frequencies of local modes of the cross girders, an experimental campaign was conducted using piezoelectric accelerometers PCB connected to a 2-channel Fourier analyser APS Signalcalc with interposition of signal conditioning units, to measure the dynamic response of these elements. These uni-axial sensors, with a sensitivity of $100 \mathrm{mV} / \mathrm{g}$, were chosen due to their particular characteristic of not needing specific power supply, operating with linear response over the frequency range of interest, having also a strong magnetic base which allows an easy and reliable fixation to the structure. The acquisition system and accelerometers are illustrated in Fig. 11.

The recording of the time series of acceleration was made during one day with a sampling frequency of $320 \mathrm{~Hz}$ and the excitation was induced manually by impact with a timber beam. The Fourier analyser incorporates filtering capacity and averaged FFTs of 6 time records were evaluated in the range $0-120 \mathrm{~Hz}$, with a frequency resolution of $0.0098 \mathrm{~Hz}$. Accelerations were measured in the vertical direction in three locations at the top flange of the extremity cross girder (R5, R12, R8), and the horizontal acceleration was also measured at midspan of this element (R13) perpendicularly to the element axis, in order to capture vibration modes with lateral movement. The different locations of the sensors can be observed in Fig. 12.

A similar test was conducted at the cross girder above the column.

Fig. 13 shows the Average Normalised Power Spectra (ANPSD) obtained for the cross girder at the extremity support. A moving average is also added in order to clearly identify peaks since it can be used as a low-pass filter to remove some of the measurement noise. The local frequencies can be related to the peaks of these spectra and different types of local modes can be also identified if taking into account the location of the measured acceleration. For the vertical direction, the frequencies $30.5 \mathrm{~Hz}$ and $24.4 \mathrm{~Hz}$ are only present in the results for location R5, this meaning that only these modes have a modal coordinate with a significant value in this location.

The analysis of the Average Power Spectrum for position R13 allows to conclude that some local modes have significant horizontal components.

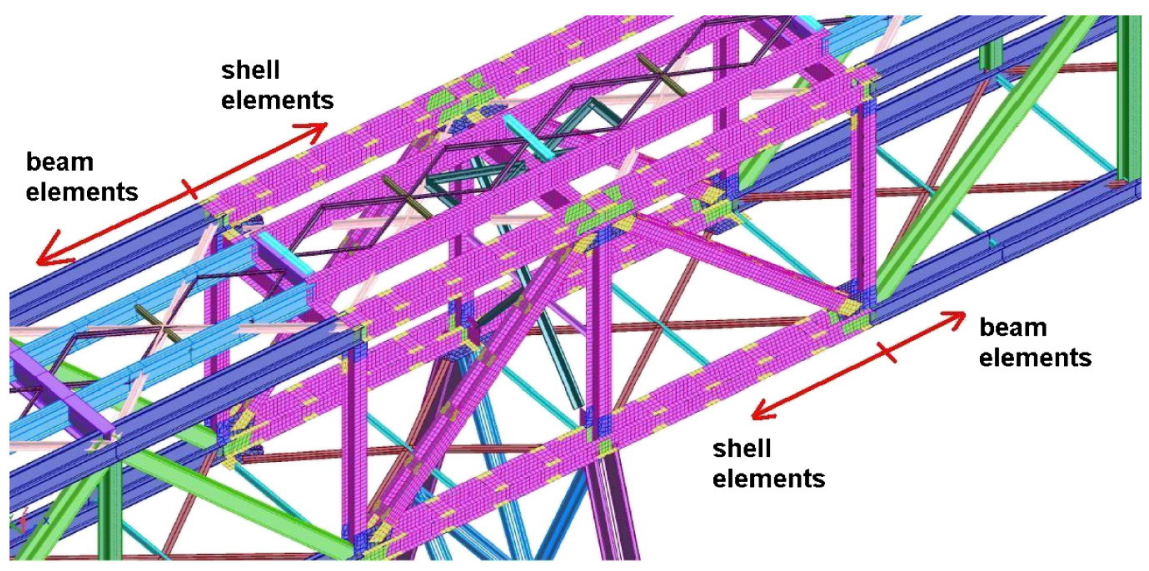

Fig. 5. FEM mesh using beam and shell elements - local view above the main columns. 

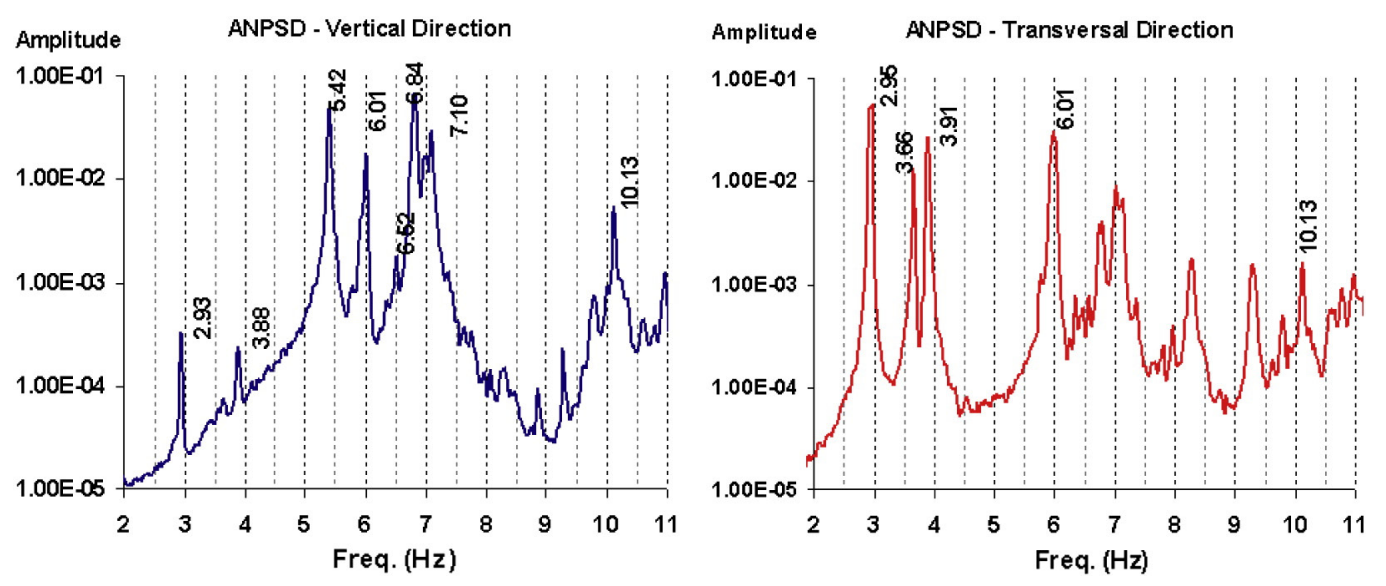

Fig. 6. ANPSD: vertical and transversal directions.

\subsection{Strain measurement campaigns}

4.3.1. Measurement of traffic induced stresses in main structural elements

An initial field strain measurement campaign was conducted at Trezói Bridge using electrical strain gauges, in order to validate the numerical simulations of the crossing of the trains and to evaluate fatigue damage indices of the principal structural elements. In Fig. 14a), the layout of the bridge instrumentation is shown. Fourteen sensors were applied to cross sections of members which experience the highest tensile stresses and four strain gauges in rail sections in the vicinity of both abutments outside the bridge in order to estimate traffic information. In some cases, the location of the sensors was defined to capture the local enhancement effect due to geometry stress concentration (Fig. 14b)). These stress enhancements were foreseen using a local shell finite element model developed in software Ansys [14], as illustrated in Figs. 14c) and 15.

The acquisition system was composed by a PXI/SCXI platform from National Instruments. A continuous recording of the readings was made with sampling rate of $100 \mathrm{~Hz}$, which is, in this case, sufficient for dynamic observations. The timeframe chosen to measure stresses in this structure was set in two days that historically have higher traffic volume, though the measured traffic volume wasn't so high as in previous years. However, during that period, 8 freight trains and 16 passenger trains crossed the bridge.

Fig. 15 presents in greater detail the location of the strain gauges placed in the bottom chord at midspan of the element with the highest stresses (locations S7, S8 and S9) and an enhanced view of the local FEM model. The nominal stresses were obtained from location S7 while the stresses enhanced due to geometric effects were obtained from location S8.
The local model illustrated in Figs. 14c) and 15 was validated using nominal stresses measured at the midspan of the structural element and the peak stresses near the joint. The stress magnitudes and the corresponding stress concentration were compared and the average calculated stress concentration factor of 1.40 was obtained and confronted with the stress concentration factor of 1.388 obtained through the measurements. These results increased the confidence in this local model hence allowing a more extensive fatigue analysis using numerical simulations. Also, the stress concentration factor was used to enhance the stress histories calculated from the beam FEM for fatigue calculations (see Section 5).

Real data obtained from the Portuguese railway agencies $\mathrm{CP}$ and Refer were used in order to compare calculated and measured stresses. The geometrical characteristics and loads of the vehicles that crossed the bridge during the measurement period were used to simulate these trains crossing using the global finite element model. The first train analysed was composed by a locomotive and four passenger wagons with 270 tons of total weight. The circulation speed was estimated using the measurements made in the rails and it was also possible to evaluate if a particular train was accelerating, breaking or maintaining a constant speed. An example of the strains measured used to the speed estimation is presented in Fig. 16, where each peak corresponds to a single axle. The distance between strain gauges was divided by the time difference between peaks of the same axle to obtain the velocity per axle. In the present case, the average estimated velocity was $30.5 \mathrm{~km} / \mathrm{h}$. An automatic processing of the data was performed using routines developed in Matlab.

The vehicle loads were estimated using the methodology described in [15-17]. This analysis led to good agreement between estimated and known axle loads.
Experimental mode shapes
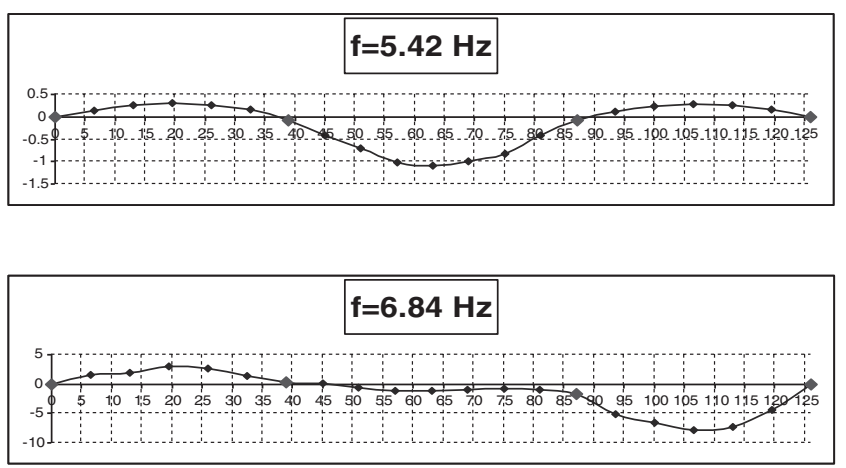

Numerical mode shapes
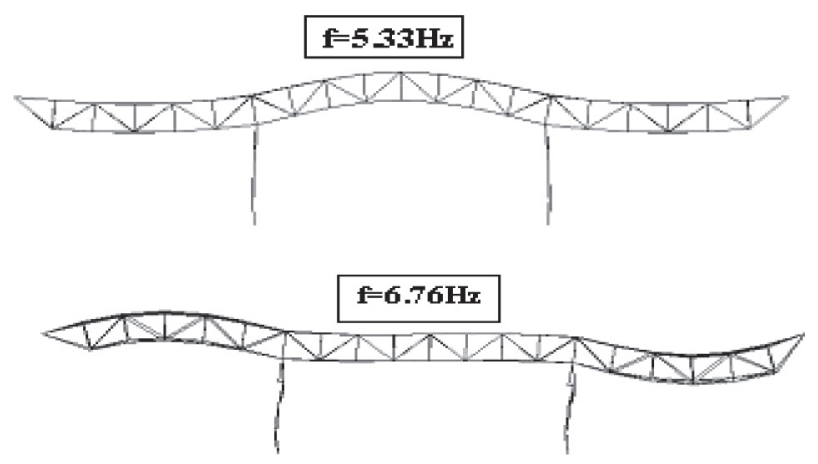

Fig. 7. Lateral view of the first 2 identified (left) and calculated (right) vertical bending modes. 
Experimental mode shape

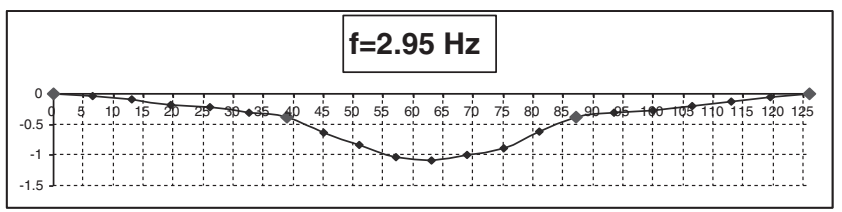

Numerical mode shape

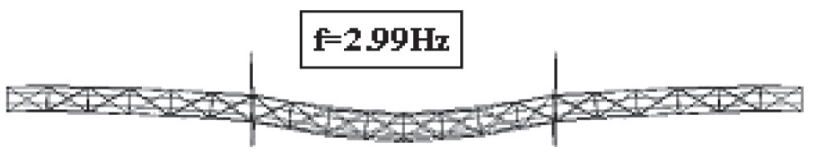

Fig. 8. Top view of the first identified (left) and calculated (right) lateral bending mode.

In Fig. 17, a comparison is made between measured and calculated stresses in the lower chord at the centre of the bridge, which is the element subjected to the highest tensile stress. The stress spectra were also compared, since they are a very useful representation of the stress history in the context of fatigue analysis. These were calculated using the Rainflow counting algorithm [21,22] implemented in Matlab.

It was concluded that the agreement between measured and calculated stresses and stress spectra is good in both cases. The small differences between the stress histories may be due, in particular, to the geometry effect of the rivets and steel plates that are not modelled in this FEM and out of plane bending moments also not detected with these numerical simulations. Nevertheless these results increased the confidence in the numerical simulation made and in the train characteristics obtained.

\subsubsection{Measurement of traffic induced stresses in the cross-girders}

As stated before, the testing and monitoring of the actual structural behaviour of this bridge is of major importance for an enhanced fatigue assessment that may take more accurately into account local vibration effects in cross-girders, as these elements are particularly sensitive to fatigue damage, as shown in Section 5. Bearing this in mind, a monitoring programme was designed to reduce the uncertainties associated with this phenomenon, namely in terms of the structural dynamic response and the trains' characteristics. Obviously, since this monitoring campaign was designed to acquire data during a long period of time, the large volume of measurements constitutes a great asset for detailed fatigue studies.

One of the most important aspects in the assessment of old structures is the estimation of real loadings, which may enable a more precise fatigue life estimation in the presence of more realistic stress spectra. With this purpose and as stated above, the monitoring system was also designed to allow the collection of data on vehicle characteristics, including velocity spectra, number of axles, axle loads and their spacing, moving directions and traffic density.

In this context, strain gauges were applied in the cross girders located at the top of the columns and at one support in the abutment in accordance with the critical locations previously identified. In addition, rail sections in the vicinity of both abutments, but outside the bridge, were instrumented with strain gauges in order to estimate the axle loads of the real trains and the corresponding velocity. The general layout of the instrumented sections is presented in Fig. 18.

Since it is not known which rivet in this cross section will induce the first crack, four strain gauges were placed in the flanges at the vicinity of the first row of rivets. These are the spots where the highest stress ranges are present and where the detail has the lowest fatigue strength making it critical in terms of fatigue evaluation. The measured strains were used to calibrate the shell finite element model described in Section 3.2 and to calculate the fatigue damage using the $\mathrm{S}-\mathrm{N}$ curves. The strain gauges were placed near the connection between the cross girder and the gusset at the vicinity of the rivets in order to capture the stress enhancement as observed in Fig. 18b).

The acquisition system is a platform from National Instruments and is composed by a computer responsible for high performance signal conditioning, which integrates two SCXI modules able to operate with 16 different channels.

4.3.2.1. Estimation of modal frequencies. To estimate the dominant frequencies present in the structural response, ANPSD of the strains measured at the extremity cross girder have been evaluated. Fig. 19 shows, for instance, such an average spectrum considering the crossing of 1533 trains. The identification of the peaks makes possible to estimate the dominant frequencies and associate them with the local mode shapes that are excited during the train crossings. However, these values may not represent all the natural frequencies of local modes of the cross-girder, as they depend on the train action and on the frequency content of the loading.

Some of the peaks identified in Fig. 19 seem to be related to global frequencies of the bridge, namely the frequencies of $5.41 \mathrm{~Hz}$ and $6.80 \mathrm{~Hz}$, which correspond to the first two global vertical bending modes, as can be observed in Fig. 7. It is interesting to notice that the structural behaviour of these secondary elements is influenced by global modes. However, observing Fig. 19 it is easy to conclude that the local modes of the cross-girders associated to frequencies above $20 \mathrm{~Hz}$ have a very important influence.

\subsection{Correlation analysis with FEM results}

The results from dynamic monitoring of local vibration effects on the cross girders were subsequently correlated with the numerical results achieved with the FEM model developed with the purpose of analysing the contribution of local modes (Section 3.2). In this context, Fig. 20 shows a comparison between calculated and identified frequencies using an ANPSD for the vertical direction obtained from the field test using accelerometers (Section 4.2). The frequency values in red are associated to this field test, the ones in blue are obtained via numerical model, and the green ones were obtained with the ANPSD calculated from strains measured with the strain gauges (see Fig. 19). Also, some local modes are represented in Fig. 21 in correspondence with the frequencies presented in Fig. 20. Generally a significant number of local modes with relevant dynamic contribution to the response can be observed, and a good agreement between numerical and experimental frequencies is found.
Experimental mode shape

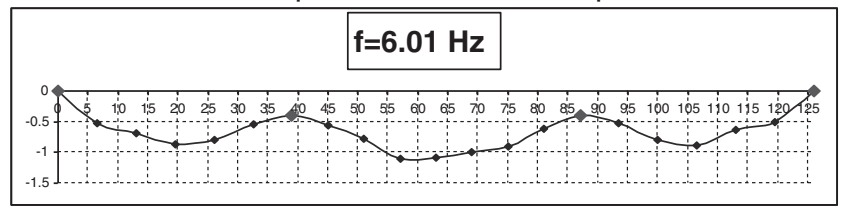

Numerical mode shape

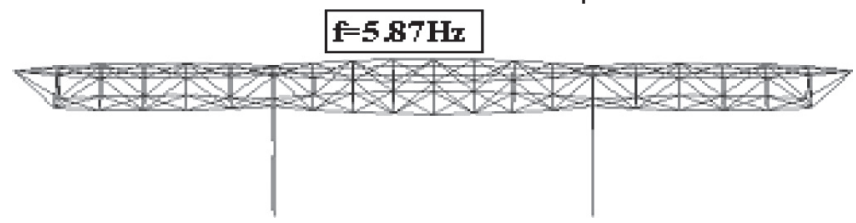

Fig. 9. Lateral view of the first identified (left) and calculated (right) torsion mode. 
Table 1

Calculated and identified natural frequencies.

\begin{tabular}{|c|c|c|c|}
\hline Identified frequency $(\mathrm{Hz})$ & Calculated frequency $(\mathrm{Hz})$ & Mode type & Variation \% \\
\hline 2.95 & 2.99 & 1st transv. bending & $1.34 \%$ \\
\hline 5.42 & 5.33 & 1st vert. bending & $1.69 \%$ \\
\hline 6.01 & 5.87 & 1st torsional & $2.39 \%$ \\
\hline 6.84 & 6.76 & 2nd vert. bending & $1.18 \%$ \\
\hline
\end{tabular}
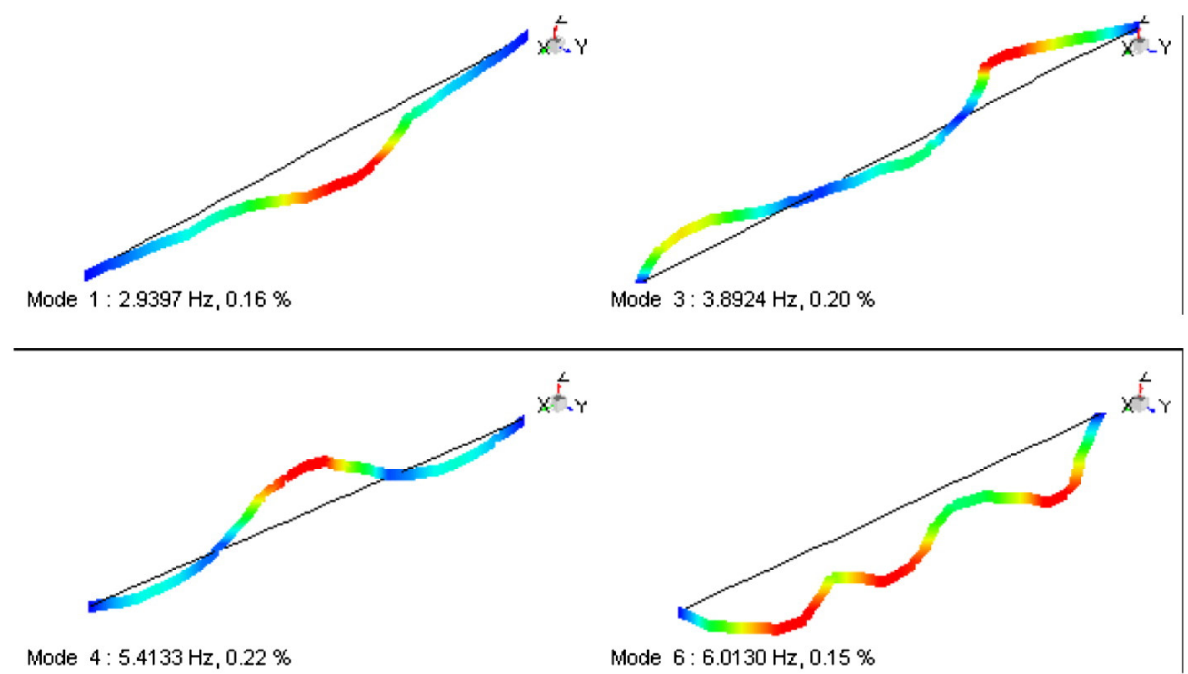

Mode $4: 5.4133 \mathrm{~Hz}, 0.22 \%$

Mode $6: 6.0130 \mathrm{~Hz}, 0.15 \%$

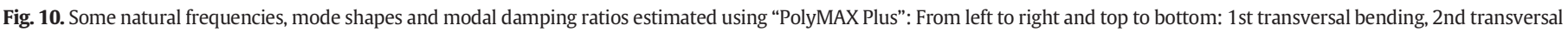
bending, 1st vertical bending, torsional mode [13].

In many of the local modes observed in the cross-girders the main cause of dynamic stresses in the spot where the strain gauges were placed is the vibration of the stringers (Fig. 21b). It is important to notice that the secondary deformation caused by these elements in the crossgirder leads to high concentration of stresses.

The local modes of the top chord can also influence the stresses in the cross girder, as is the case of the local mode presented in Fig. 21a) (frequency of $30.1 \mathrm{~Hz}$ ). In this case, the lateral vibration of the chords leads to a bending deformation in the cross girder which enhances the stresses in this element, and in particular in the location where the strain gauges were placed.

Further correlation analyses were made in order to get additional confidence in the developed FEM using the numerical simulations of the trains' crossings and the data from the field measurement campaign with strain gauges. To achieve this goal, the stresses measured at the cross-girder at the vicinity of one of the columns were compared with the corresponding calculated stresses. Fig. 22a) and b) presents a partial view of the structure with indication of the location of this strain gauge and the corresponding finite element mesh used in the discretisation.
The train that crossed the bridge at the time of measurement was composed by a locomotive and 7 passenger vehicles.

The results obtained are presented in Fig. 22c), where the red graphic corresponds to the measured stresses and the blue one to the calculated. The agreement between both graphics is good and it can be observed that the model can capture the stress variation with a reasonable level of accuracy. However, the model underestimates the stresses in the real structure which may indicate the necessity to model the rivets, the contact and the friction between elements of the connection. This difference may be related to the stress enhancement due to the rivet hole and eventually due to the slip between elements that may induce stress paths unforeseen in the model.

\section{Fatigue analysis and identification of critical elements}

The identification of the critical structural elements in the context of fatigue assessment is a complex task, due to the random nature of the load, the local dynamic amplification and the non-linearity of the resistance. Hence, the most stressed element may not be the element in

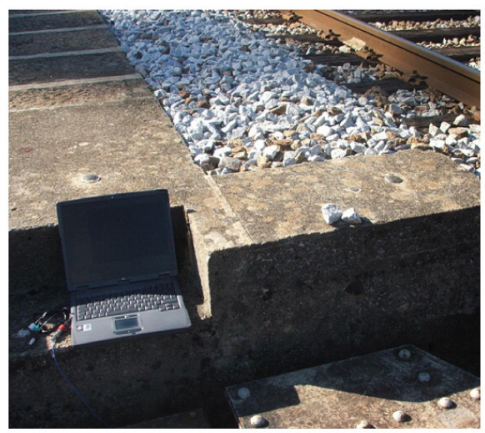

(a)

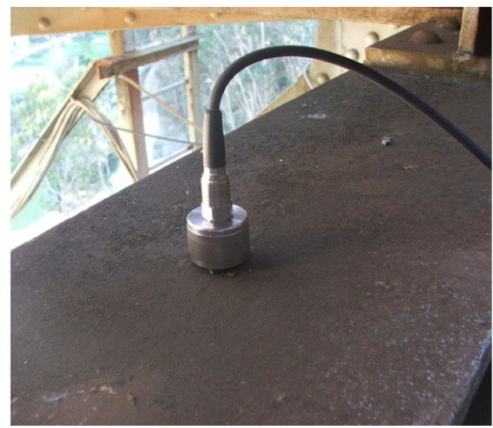

(b)

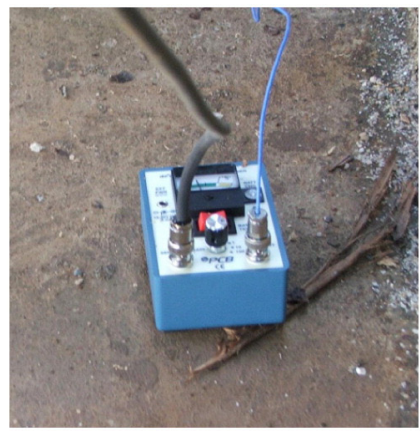

(c)

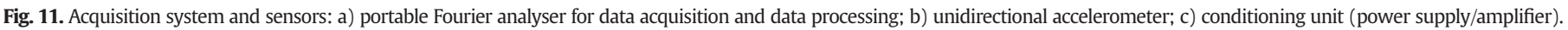




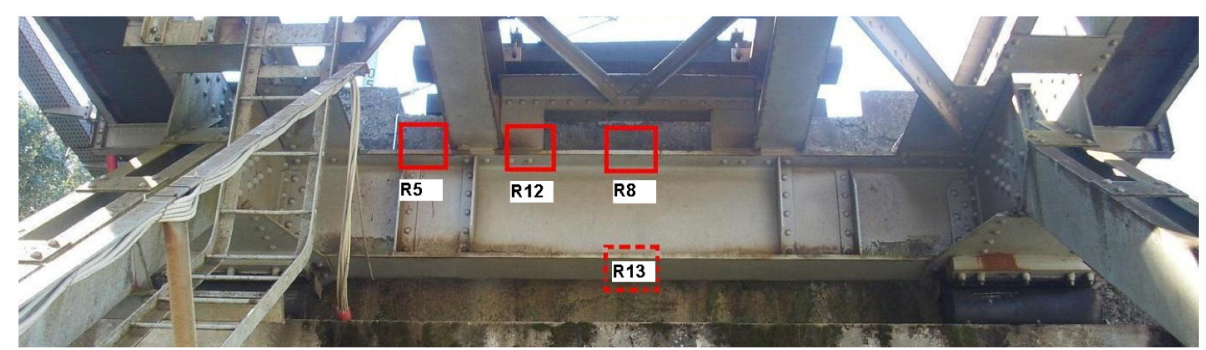

Fig. 12. Locations of the accelerometers at the extremity cross-girder.

which fatigue is conditioning in terms of safety: two details with the same S-N curve may have very different stress spectra, one with small number of cycles associated with high stress ranges and the other with high number of cycles associated with lower stress ranges. As can be understood, the second detail may have higher fatigue damage in spite of lower stresses. In this context it is necessary to analyse all the elements of the bridge in terms of fatigue behaviour. The following sections describe these calculations made using the EN1991 [18] traffic scenarios, as well as real traffic scenarios.

\subsection{Fatigue detail classification}

The European code prescriptions include the possibility of implementation of dynamic analysis for simulation of specific real trains, the Eurocode fatigue trains [18]. The European norm EN1993-9 [19] defines the rules for the calculation of fatigue resistance using the Whöller curves

$\Delta \sigma_{R}^{m} \times N_{R}=\Delta \sigma_{C}^{m} \times 2 \times 10^{6}, m=3, N_{R} \leq 5 \times 10^{6}$

$\Delta \sigma_{R}^{m} \times N_{R}=\Delta \sigma_{D}^{m} \times 5 \times 10^{6}, m=5,5 \times 10^{6}<N_{R} \leq 10^{8}$

$\Delta \sigma_{L}=\left(\frac{5}{100}\right)^{1 / 5} \Delta \sigma_{D}$

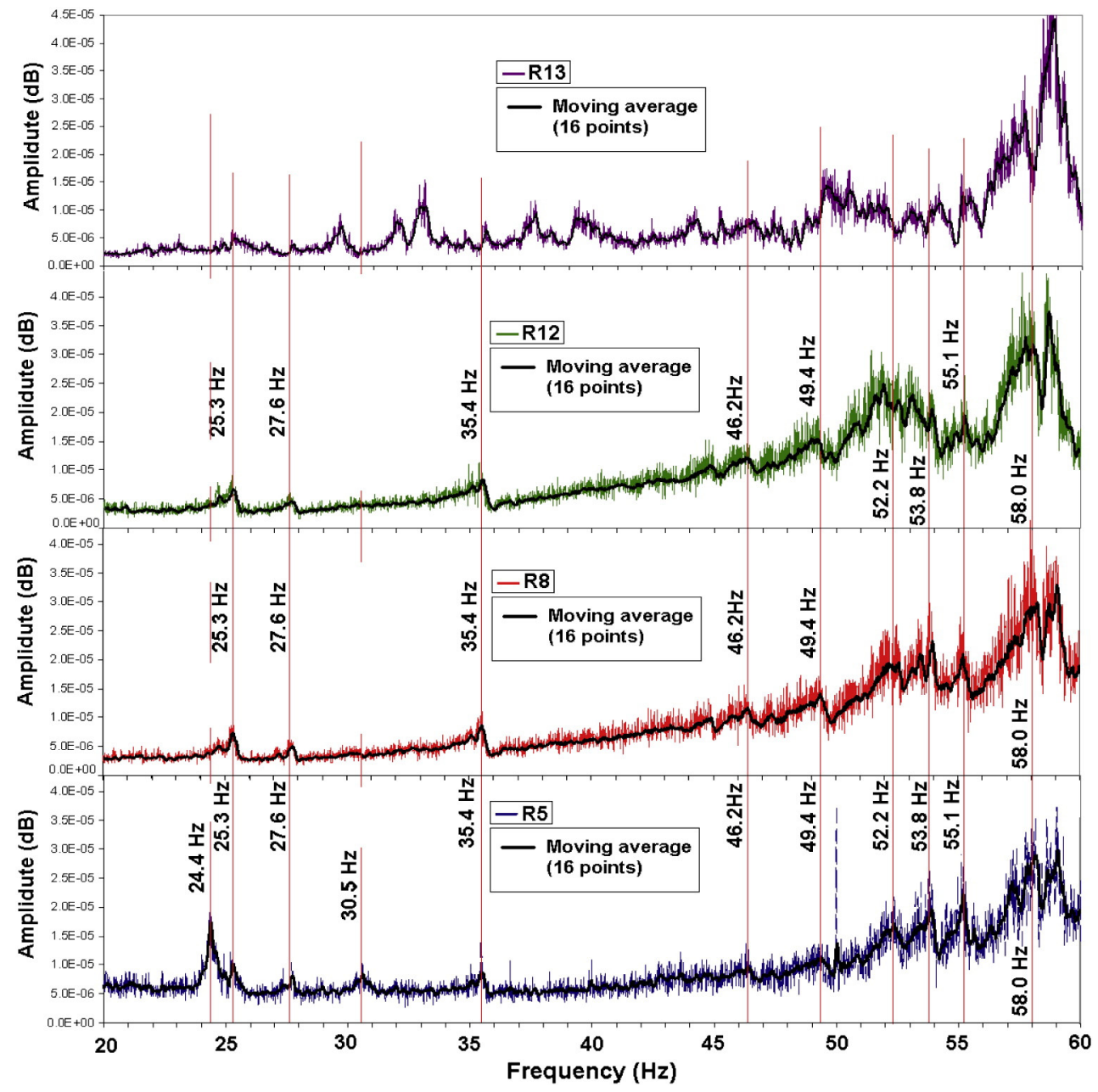

Fig. 13. Average normalised power spectra. 


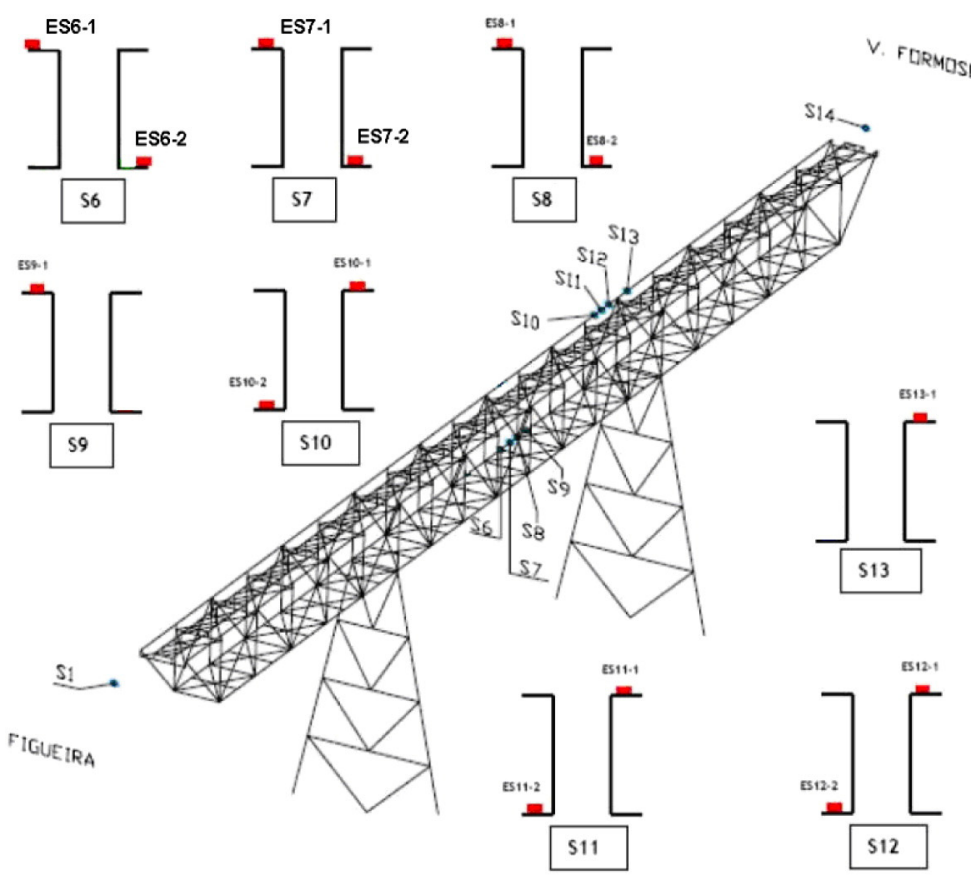

(a)

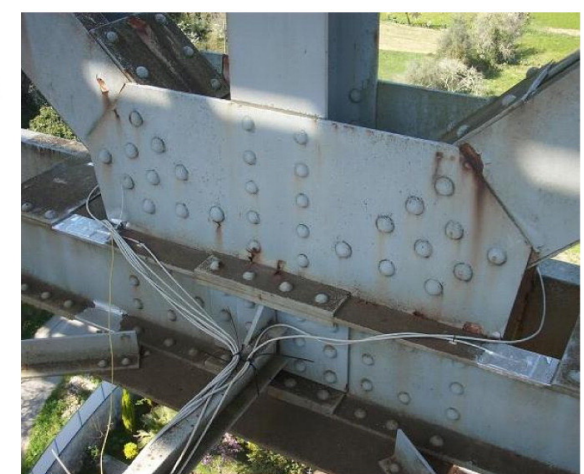

(b)

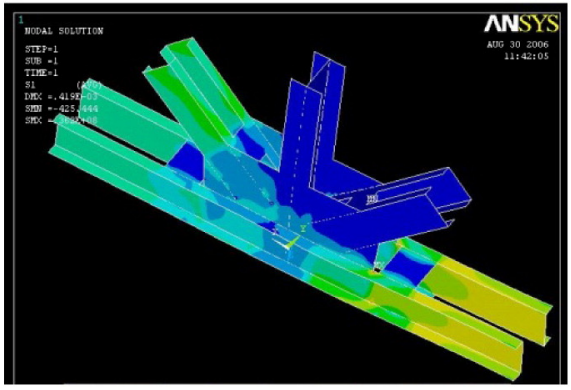

(c)

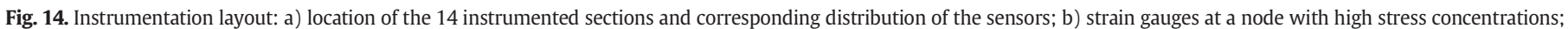
c) corresponding finite element model.

and fatigue damage (D) using Miner rule

$D=\sum_{i} \frac{n_{i}}{N_{i}}$

In Eqs. (1) to (3), $\Delta \sigma_{\mathrm{R}}$ is the fatigue strength in terms of stress amplitude, $N_{R}$ is the fatigue strength in terms of number of cycles to failure, $\Delta \sigma_{\mathrm{c}}$ is the reference value for fatigue strength at 2 million cycles, $\Delta \sigma_{\mathrm{D}}$ is the constant amplitude fatigue limit and $\Delta \sigma_{\mathrm{L}}$ is the cut-off limit. Finally, in Eq. (4), $n$ is the number of cycles associated with each stress range.

However, the absence of a specific curve for the analysis of riveted details is a major drawback of the Eurocode 3. Taras and Greiner [20] conducted a research where several Whöler curves for different structural details were studied and, particularly, riveted details were analysed in order to conclude about the best curve to represent its fatigue behaviour. The conclusion was that the Eurocode curve 71 fitted best the details and was the most adequate for the analysis of such riveted components.

To further investigate the adequacy of curve 71 for riveted details, an experimental programme was carried out with the original material extracted from the bridge [23]. A bracing $3000 \mathrm{~mm}$ in length was removed from the structure and 8 specimens were extracted from this structural element for $\mathrm{S}-\mathrm{N}$ investigation. In Fig. 23 the results from this experimental campaign are compared with results obtained from other experimental campaigns with material from other Portuguese bridges.

It can be concluded that the majority of the results are above the $\mathrm{S}-\mathrm{N}$ curve for detail class 71 thus justifying the use of this curve for fatigue evaluation in the case of Trezói bridge.

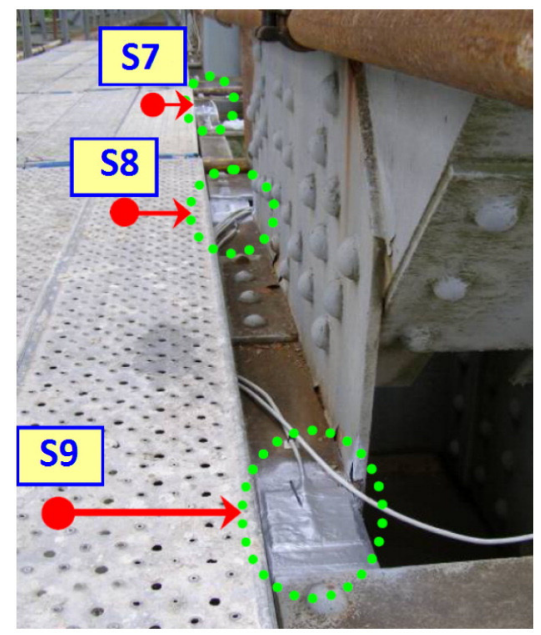

(a)

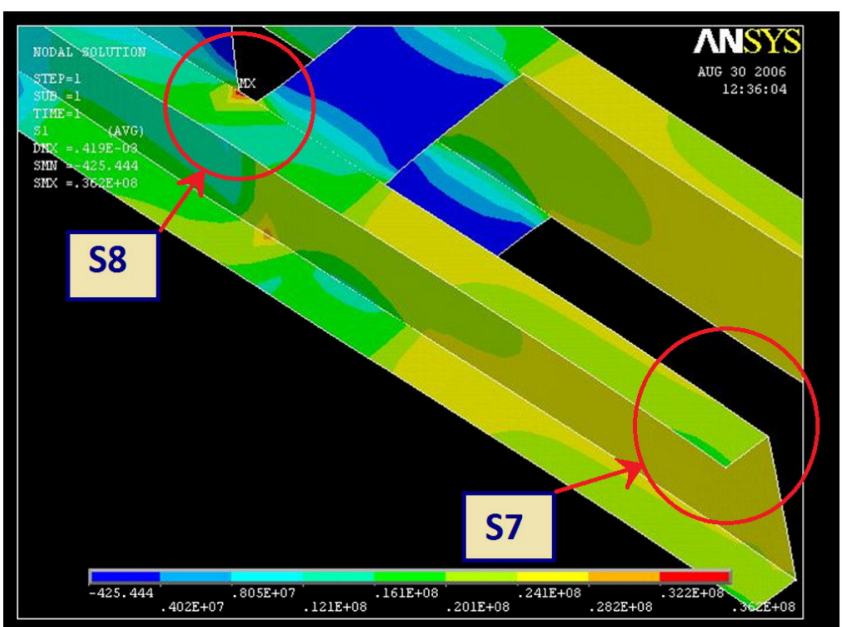

(b)

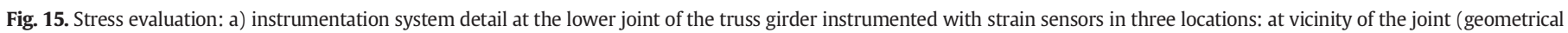
stresses, S8 and S9) and at midspan of the element (nominal stress, S7) in correspondence with the numerical stress analysis; b) local view of the local FEM. 


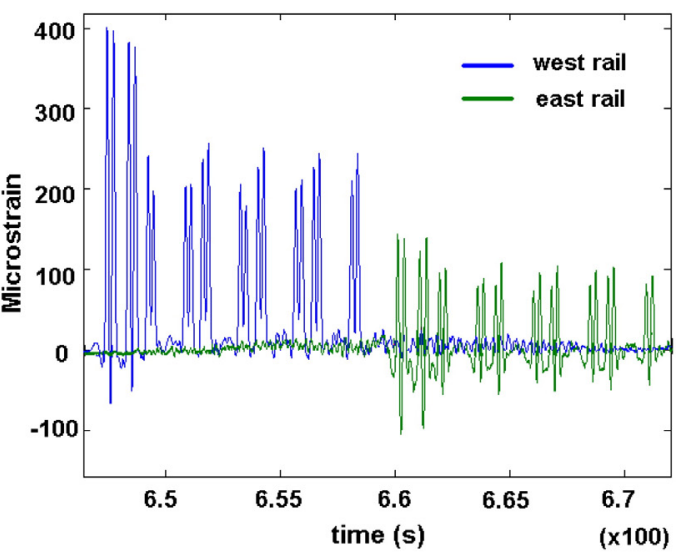

(a)

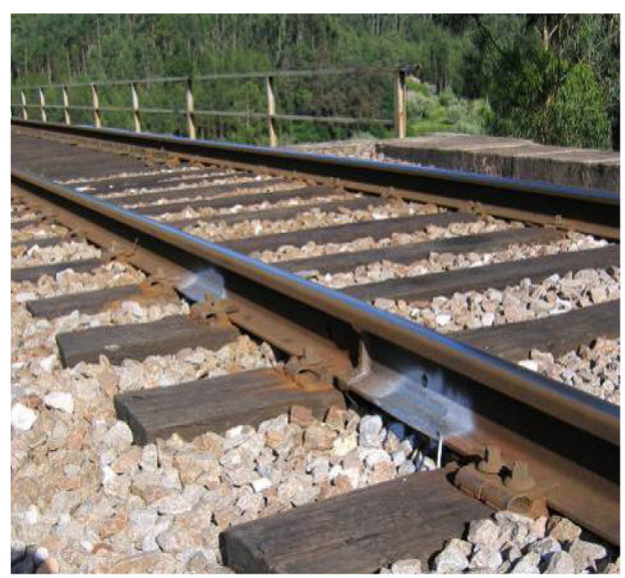

(b)

Fig. 16. Strain measured in rail sections in the vicinity of both abutments outside the bridge (east and west).

\subsection{Fatigue analysis based on Eurocode traffic scenarios}

The stress spectra of all the elements of Trezói Bridge were evaluated using the EN1991 fatigue trains and the three traffic mixed and, following the recommendations of [20], damage being calculated using fatigue curve 71 of EN1993-9.

A total of 256 structural elements were analysed in order to identify the most sensitive elements to fatigue loading. Fig. 24 summarises the damage indices obtained for all the elements considering the present age of the bridge and assuming the EN1991 Heavy Traffic scenario. A first conclusion can be made: there is a high number of elements with a damage index higher than 1.0, which means that they would collapse under the conditions specified in this code. The upper and lower chords are the elements with the highest stresses. However the highest damage values clearly occur at the cross girders. These elements have typically the highest damage values, since they suffer direct influence of each train axle, which leads to at least one stress cycle for each axle. For this reason, they are submitted to greater number of cycles than other principal structural elements.

\subsection{Fatigue analysis based on real traffic and on measurements}

The same calculations were made using real traffic data obtained from records of the Portuguese railway agencies CP and Refer for this specific bridge in the period of 2001 to 2006, assuming the traffic conditions in this period are conservative in terms of the bridge lifetime. The corresponding present damage indices are shown in Fig. 25 and clearly a difference in the magnitude of the damage is observed with regard to the one obtained based on the EN1991 Heavy traffic scenario. Damages are lower than the ones obtained from the calculations based on the Eurocodes, certainly due to the fact that the real traffic is significantly lower than the assumed in EN1991.

As can be observed in Fig. 25, the highest damage is 0.74 for the cross-girder at the extremity support. The total fatigue life is 77.03 years (in correspondence with a damage index of 1.0) and, accordingly, the remaining fatigue life is 20.03 years. Since this value is lower than the design life (100 years), this result suggests that the past traffic was eventually higher than predicted in the original design and/or the dynamic effects may be leading to the increase of damage.

To enhance the confidence in these results, fatigue damage was calculated using the stress histories measured during the developed temporary monitoring campaign (see Section 4.3.1). Since the strain gauges were then placed only in the main structural elements (upper and lower chords), it was not possible to evaluate the damage in the cross-girders. However, comparisons in the chords were conducted.

All 14 instrumented sections of the bridge were analysed for each train passage. The corresponding results are presented in Fig. 26 for the 1st day of measurements, where it can observed that damage is highest at sensors 1 to 6 .

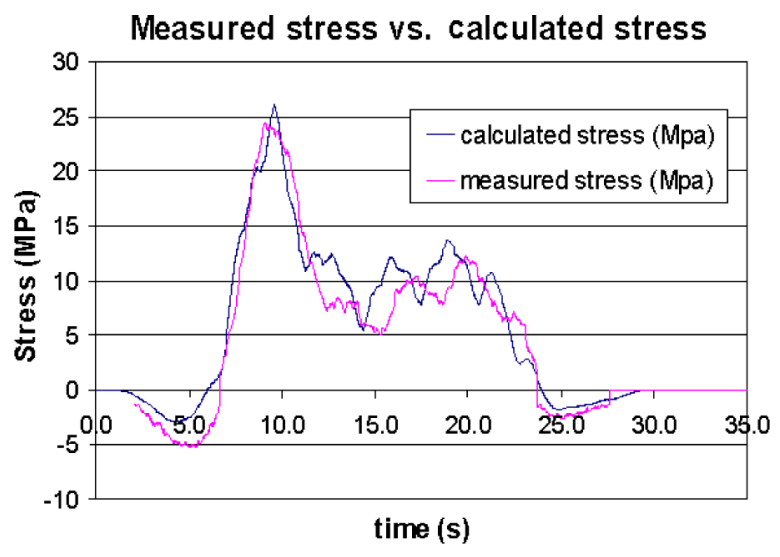

(a)

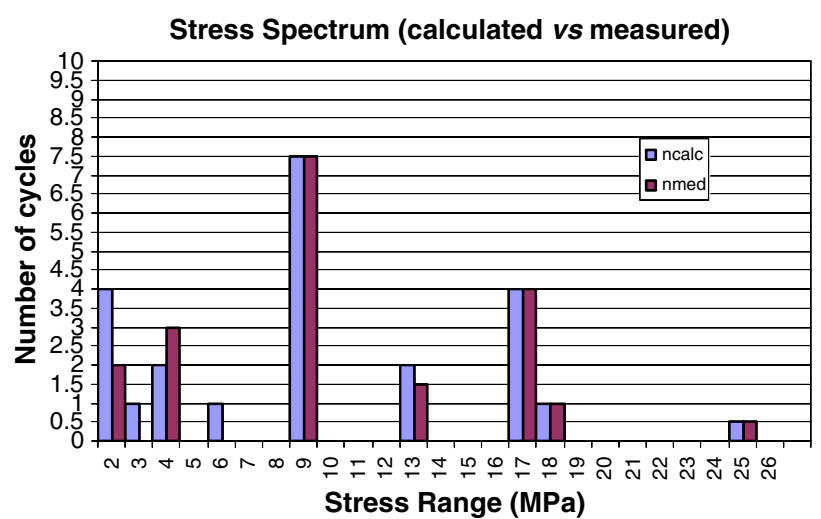

(b)

Fig. 17. Comparison between numerical and calculated results: a) measured vs. calculated stresses; b) measured vs. calculated fatigue stress spectrum. 


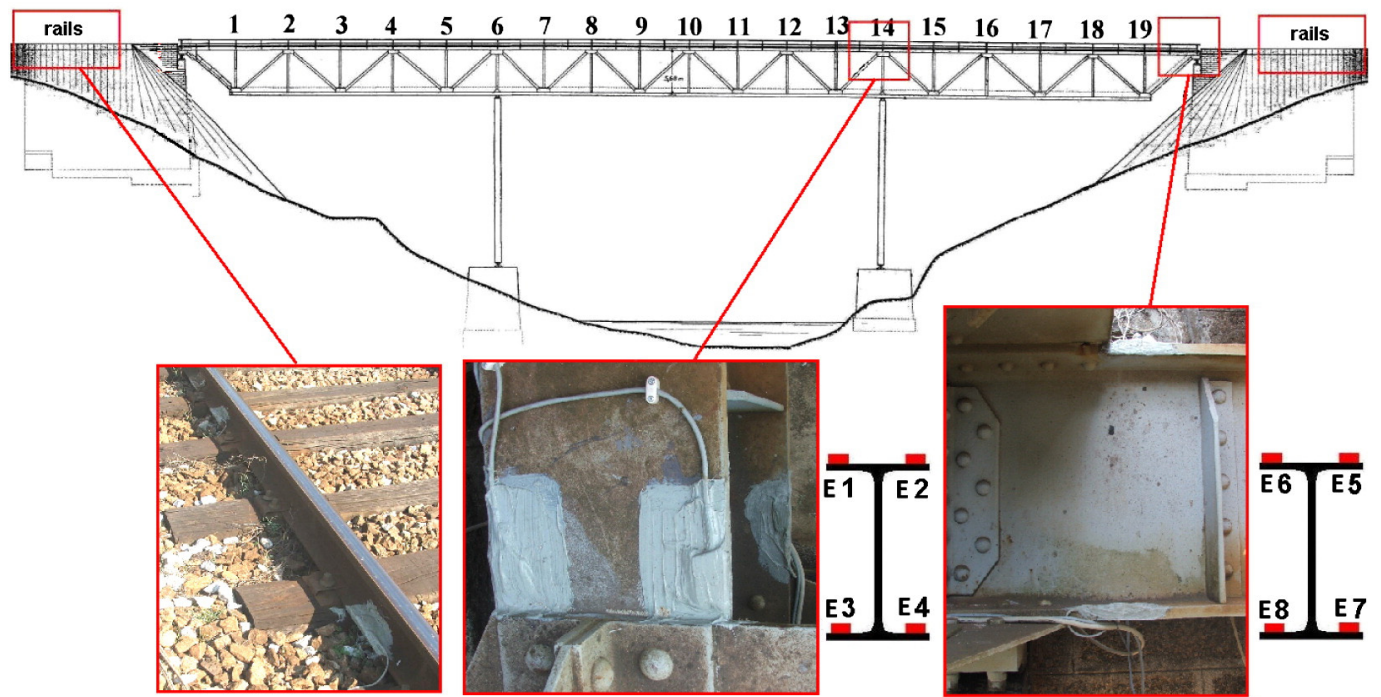

(a)
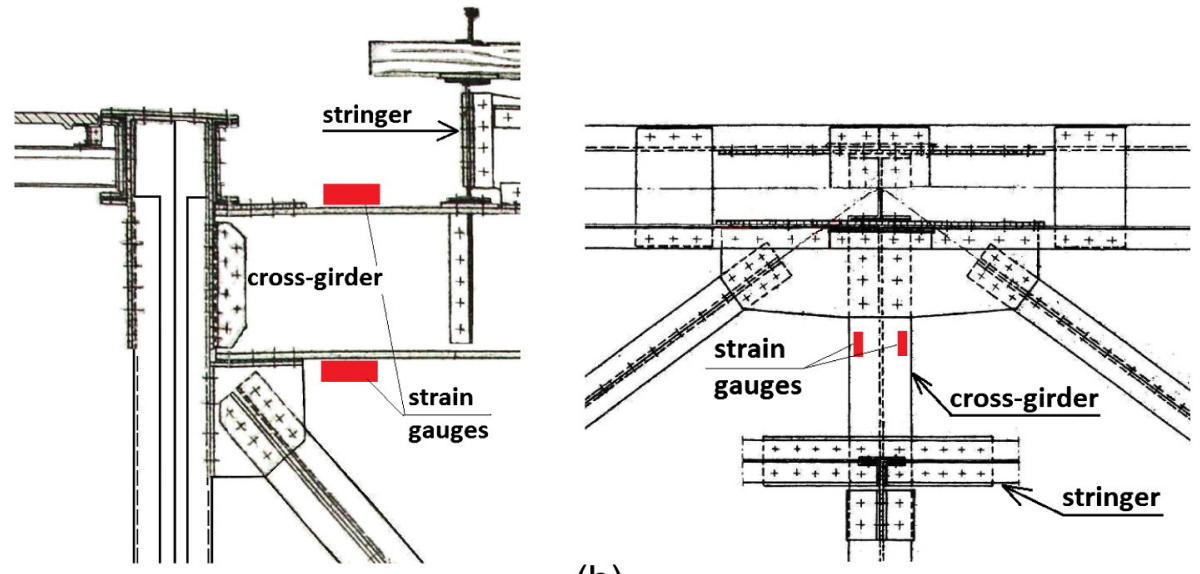

(b)

Fig. 18. Location of strain gauges: a) global view; b) lateral view (left) and top view (right).

For validation purposes, the corresponding damage at those locations was also calculated using numerical simulations of the trains that crossed the bridge during the measurement campaign.

There is a reasonable agreement between damage indexes calculated from measured strains and calculated from simulations made with the FEM with beam elements. It should be noted that the stresses obtained in correspondence with the strain gauges in the joints were

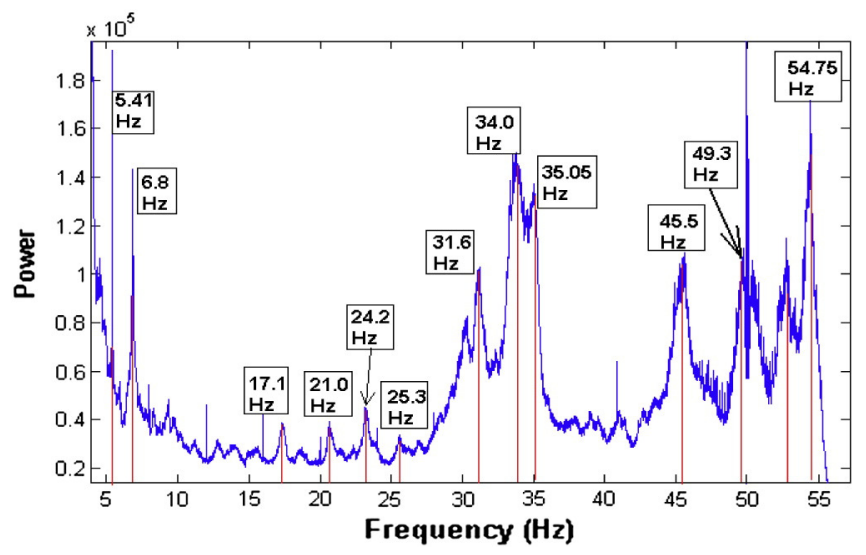

Fig. 19. Average power spectrum of measured strains induced by 1533 trains. multiplied by the stress concentration factor obtained from the local FEM of the connection between the chord, diagonal and vertical element described in Section 4.3.1. However, some discrepancies are observed in some locations of strain gauges close to the connection between chords and other structural elements. These are probably related to unforeseen load distribution in the real structure.

\subsection{Importance of local vibration}

Inspection of the results of the global fatigue assessment clearly shows that there are some structural elements with much higher damage, which are the cross-girders at the extreme supports and above the columns. The location of these elements is better characterised in Fig. 27. This was expected because the train loads are almost directly applied to these elements, which implies a high sensitivity to cycle variation and local loading effect. On the other hand, the structure works as a low-pass filter for the main elements (chords, diagonals, etc.) which, for that reason, don't exhibit a high number of response cycles.

In an extensive study of riveted steel bridges in the USA [3], it was concluded that the majority of fatigue problems arise from bad conception of structural details. This leads to out-of-plane loading, secondary moments, vibration fatigue and distortion. In particular, the crossgirders are prone to such problems. In old bridges, the common misalignment of the rails with the axle of the stringers leads to an eccentric loading outside the plane of these elements, which creates stresses not 


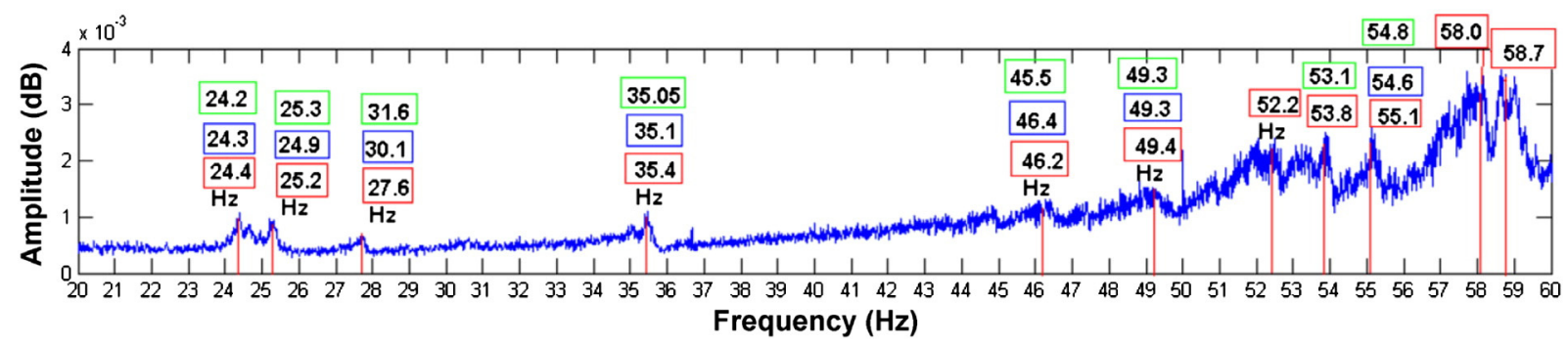

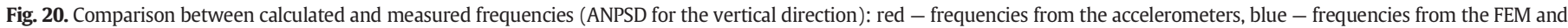
green - frequencies from ANPSD of measured strains. (For interpretation of the references to colour in this figure legend, the reader is referred to the web version of this article.)

foreseen in the cross-girders and cracks due to load path detectable only with more complex finite element models. Also the vibrations that occur in these elements induce stress cycles that cannot be evaluated with simple models.

In the particular case of Trezói Bridge, the first natural frequencies of the cross-girders fall in the range of the loading frequencies, increasing the concern to adequately characterise the structural behaviour of these elements. These considerations justify the development of the local FEM described in Section 3.2.

\subsection{Fatigue analysis of the cross-girders}

5.5.1. Influence of the local modes in the dynamic behaviour and in fatigue

A first stage of the fatigue analysis was conducted to evaluate which modes have the highest influence in the phenomenon. For that purpose, several modal analyses were made using the finite element models described in previous sections.
To conclude about the local modes that contribute the most for vibration induced fatigue, a numerical analysis of the stress history calculated at the location presented in Fig. 22a) was conducted. This stress calculation was made using results from the FEM in the vicinity of the riveted connection between the top flange of the cross girder and the top chord. This location corresponds to the spot where the stress is higher, due to the existence of the rivet holes which leads to stress concentration, and the fatigue resistance is lower as can be concluded observing the Whöler curves prescribed in the EN1993-9 [19].

In this context, a frequency domain analysis was performed, for instance, for the stress history obtained from the simulation of a freight train composed by a locomotive and 6 wagons as represented in Fig. 28. This analysis allowed to conclude that in this case there is some influence of the local modes with frequencies within the range of $15 \mathrm{~Hz}$ to $40 \mathrm{~Hz}$. However, the most important contribution is associated to the local modes within the frequency range of $45 \mathrm{~Hz}$ to $55 \mathrm{~Hz}$ as illustrated in Fig. 28b). These frequencies correspond to some of the local modes of the cross girders previously identified.

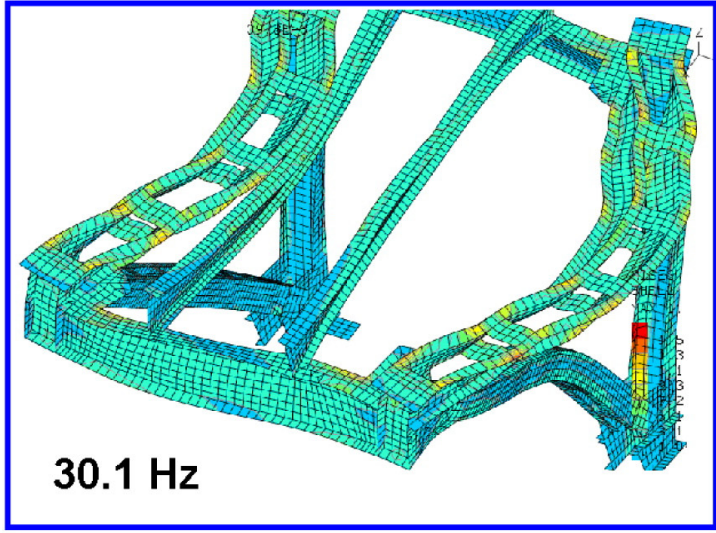

(a)

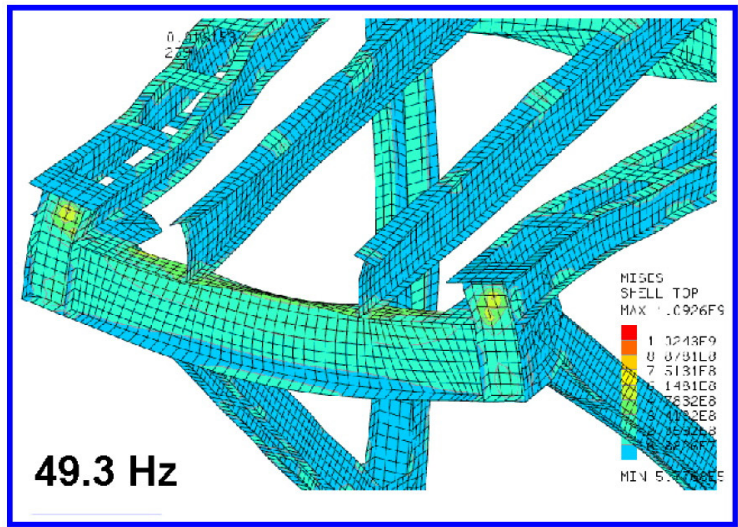

(c)

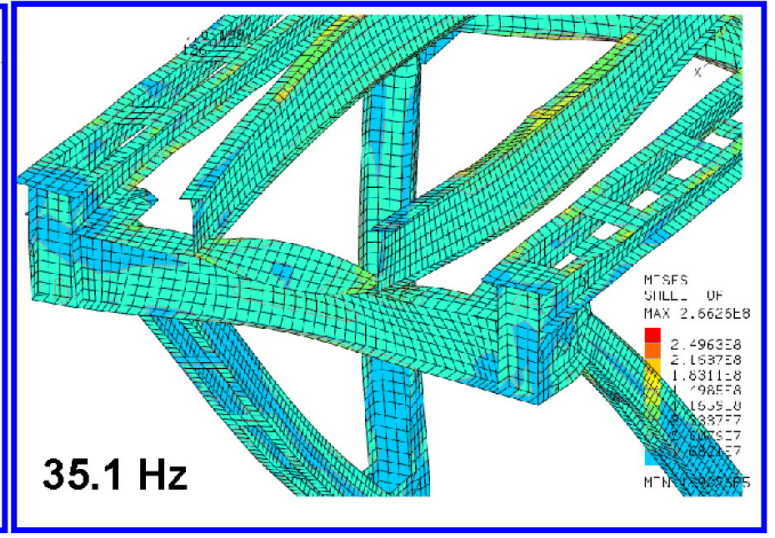

(b)

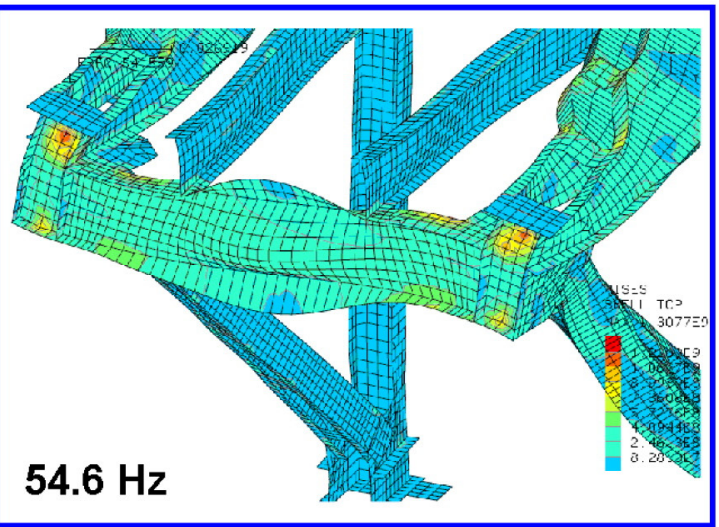

(d)

Fig. 21. Local modes of the cross-girder at the extremity support: a) vertical bending mode; b) lateral bending mode; c) vertical bending mode; d) torsional mode. 


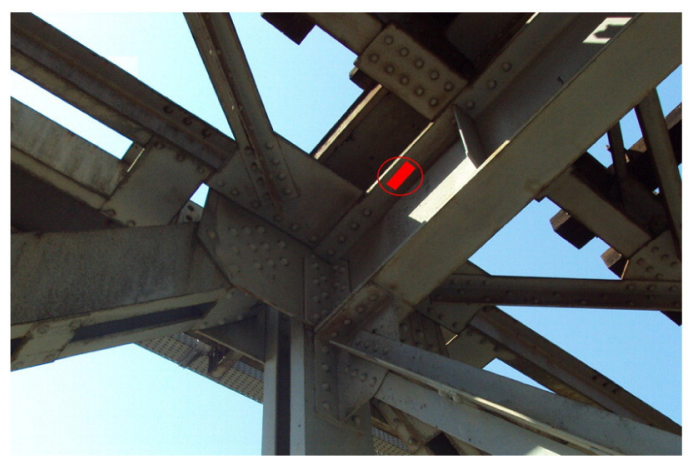

(a)

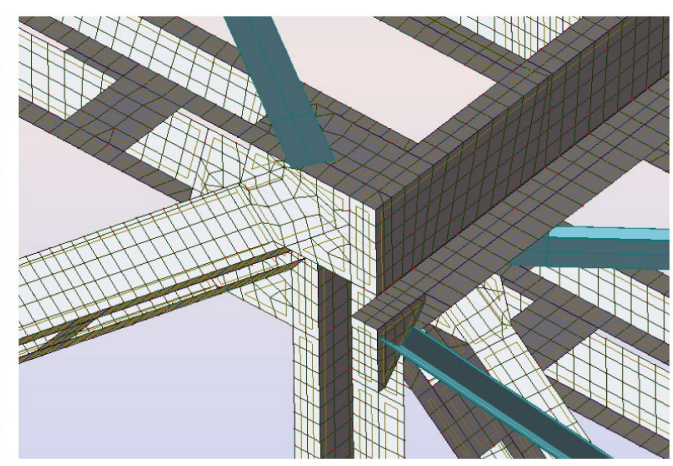

(b)

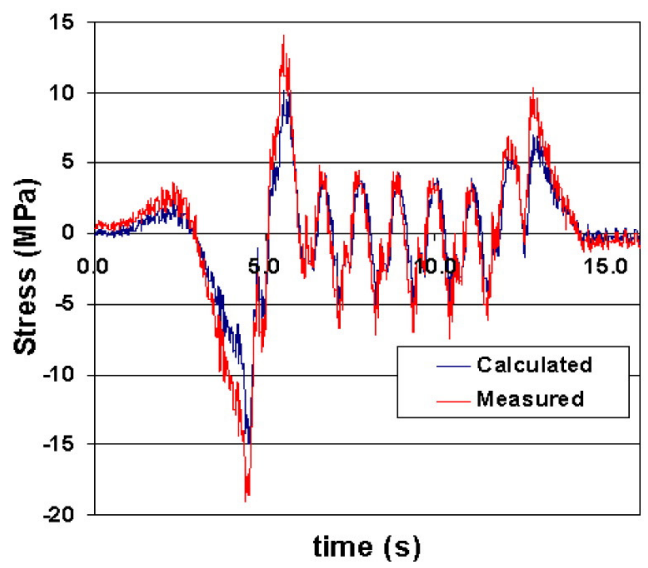

(c)

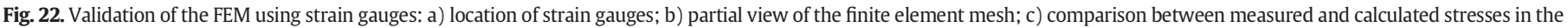
cross-girder. (For interpretation of the references to colour in this figure, the reader is referred to the web version of this article.)

To understand the influence of these modes on the dynamic response of the bridge, several dynamic analyses of the bridge response under the freight train crossing were conducted with increasing number of modes included in the modal analysis. The lowest cutting frequency is $5 \mathrm{~Hz}$, whereas the maximum value of the highest cutting frequency is $65 \mathrm{~Hz}$, allowing the consideration of all the main global modes, as well as of the most relevant local modes of the cross-girders.

In Fig. 29a) the effect of variation of the upper cutting frequency in the extreme values of stresses at the cross girder at the extreme support is presented. There is a very high increase in the minimum and maximum values of the stresses around the frequency of $50 \mathrm{~Hz}$. This is easy to understand because one of the local bending modes of this element has a frequency of $49.26 \mathrm{~Hz}$ (see Fig. 21). In Fig. 29b) the influence of the local modes on fatigue was evaluated. This was accomplished by calculating the damage of the cross girders using the simpler initial model with beam finite elements and comparing these results with the damage evaluated using the stress spectra obtained from the shell elements FEM for different cutting frequencies. It is easy to conclude that the fatigue damage has a small variation for almost all values of the upper cutting frequencies for the case of the bar model. However, for the case of the shell model, there is a very high increase of the fatigue damage at frequencies within the range of $49 \mathrm{~Hz}$ to $55 \mathrm{~Hz}$, which are precisely frequencies corresponding to the main local modes of the cross girders. The corresponding stress histories are presented in Fig. 29c) for the lower cutting frequencies and in Fig. 29d) for the higher cutting frequencies.

This means that a fatigue assessment based on a beam finite element model can clearly underestimate the fatigue damage in the cross-girder due to the importance of local modes that are only correctly captured by the shell model. These local modes are not correctly captured by the beam model because they have important deformations related to the distortion of the section and local bending of the flanges. Also, the geometry of the connection between the cross-girder and the top chord, diagonal and vertical element leads to stress patterns that are not present in the beam model.

5.5.2. Fatigue damage calculation using measurements in the cross-girders

The Palmgreen-Miner rule and the EN1993-9 S-N curve were used to calculate the damage during a period of 1 year and 5 months for each of the 8 locations of the strain gauges placed on two crossgirders of the bridge as described in Section 4.3.2. It was concluded that it is in the strain gauge E6 that the maximum damage is present.

The mean stress effect due to weight of the structure was taken into account with the Goodman criteria [24]. However, the influence of means stress in the fatigue damage is, in this case, very small since the stresses in the cross girders due to dead weight is within the range of 1.1 MPa to 8.6 MPa.

The stress spectrum calculated from strains measured using this strain gauge E6 is presented in Fig. 30 together with the S-N curve for the detail category 71 of the Eurocode. As expected, the lower stress ranges correspond to a higher number of cycles. However, the higher stress ranges lead to higher damage values.

The damage per crossing is presented in Fig. 31 where it is possible to observe a seasonality effect since the damage is lower for the summer months which normally also have lower traffic.

The total damage during the period in consideration and for the location of strain gauge E6 is 0.015035 . Assuming the hypothesis that the damage obtained for this period is representative of the average damage in the past and assuming a future traffic growth of $1.5 \%$ a year, the present damage index is 0.605 and the corresponding residual life is 31 years. 


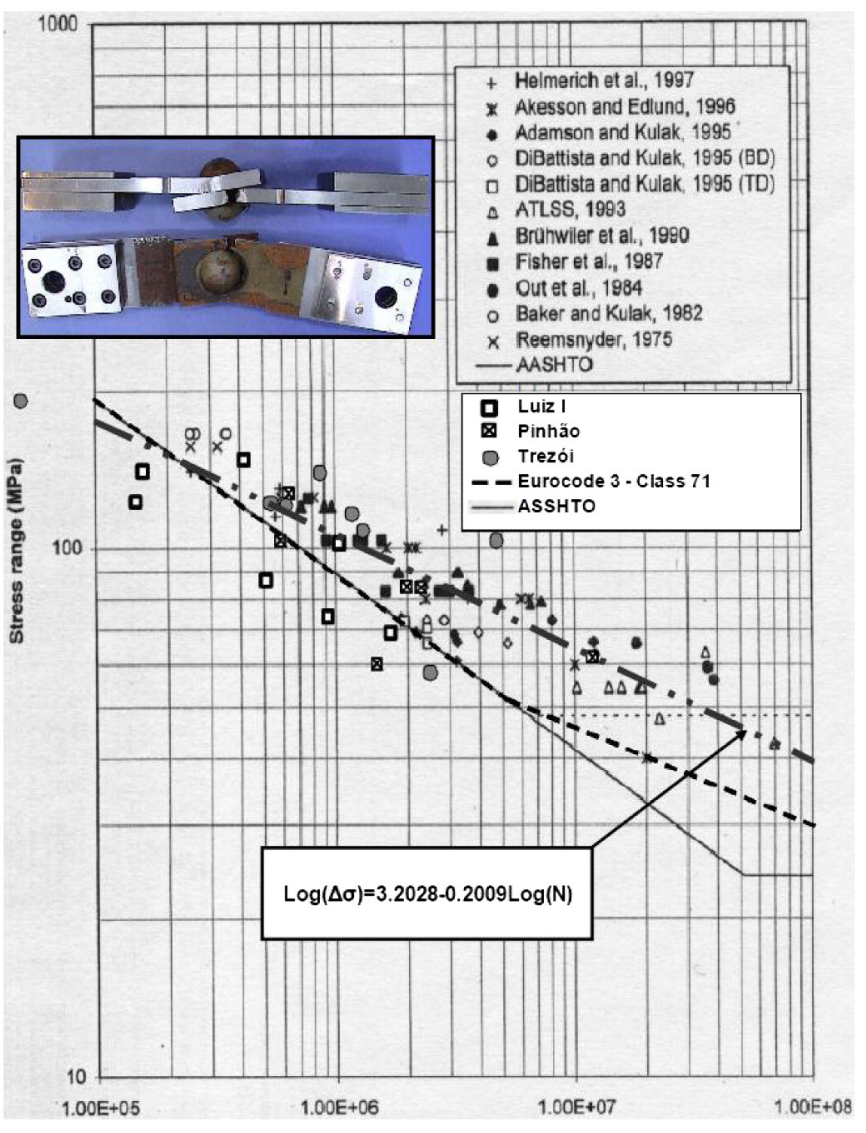

Fig. 23. Experimental results for the S-N curve detail investigation [23].

In Figs. 32 and 33, each damage index for the period of measurement is plotted in correspondence with the train characteristics that led to that damage. These characteristics are the velocity, the number of axles and weight per length.

An interesting result can be observed in Fig. 32 where the higher damage values are associated to a number of axles between 20 and 40 , and a weight per length between 20 and $35 \mathrm{kN} / \mathrm{m}$. These results suggest that important dynamic effects are amplifying the damage values since it would be expected that higher weight per length would lead to higher damage.

The results presented in Fig. 33 also support this hypothesis. In this figure it is possible to observe that, in general, higher velocities

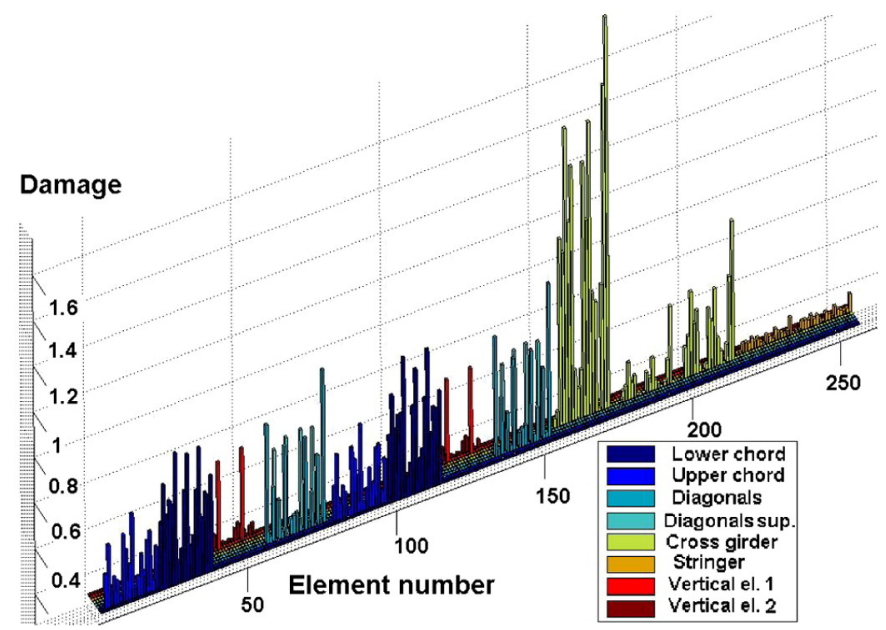

Fig. 24. Fatigue damage indices for all structural elements for the EN1991 Heavy Traffic scenario.

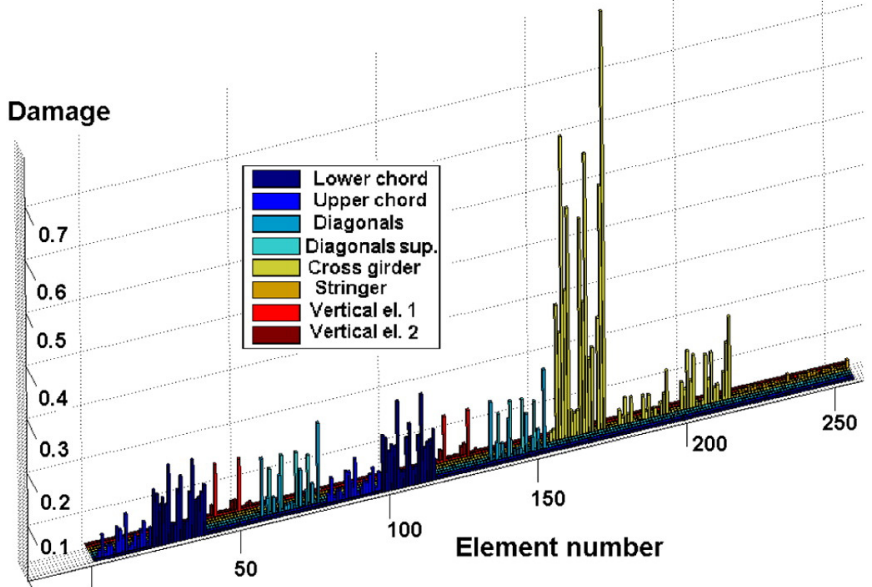

Fig. 25. Fatigue damage indices for all structural elements for real traffic scenario.

correspond to higher damages. In particular, this effect is more prominent for values of weight per length within the range of 20 to $40 \mathrm{kN} / \mathrm{m}$. This means that some specific combination of loading frequencies (velocity of circulation divided by the axle spacing) may be exciting important modes of the structure.

\section{Conclusions}

This paper describes the experimental and numerical studies conducted by the Laboratory of Vibrations and Monitoring (ViBest) of FEUP to evaluate local fatigue effects in a Portuguese metallic riveted bridge, the Trezói Bridge. The following tasks were concluded in order to achieve this goal:

- A global finite element model using 3D beam elements was developed in order to evaluate the global dynamic behaviour of this structure. This model was useful, in particular, to better understand the level of importance of the train-bridge interaction effect. It was concluded that the train-bridge interaction effects are negligible for the speed range allowed for this bridge.

- A preliminary ambient vibration test was performed, which was essential to 'tune' the developed numerical model subsequently used to simulate train crossing and calculate stress spectra. It was found that the beam FEM reproduced the global mode shapes with sufficient accuracy;

- A temporary monitoring campaign developed with electrical strains gauges was essential for the experimental validation of the numerical simulations, and the comparisons made between calculated and measured strains increased significantly the confidence in the FEM. The numerical and experimental analysis of the connection between the most stressed element (bottom chord) and the diagonals showed that for the bottom chord the stress concentration factor is approximately 1.40 . This stress concentration doesn't take into account the rivet hole. This result suggested that the rivet hole has a small influence in the stress concentration factor. However, further numerical analysis must be developed taking into account contact and friction in the rivets to conclude about the stress state in this joint;

- Simulations of the bridge crossing assuming real traffic and the EN1991 traffic scenarios allowed the fatigue assessment of all structural elements and it was concluded that the elements with the highest damage indexes are the cross-girders which are not the most stressed elements. This is due to the existence of a high number of stress cycles and the sensitivity of these elements to local loading. Also, fatigue was assessed using the strains measured in the temporary monitoring campaign and compared with the fatigue calculated at the corresponding locations and real trains. It was concluded that the agreement between fatigue indexes calculated with numerical 
Damage per crossing (from measurements)

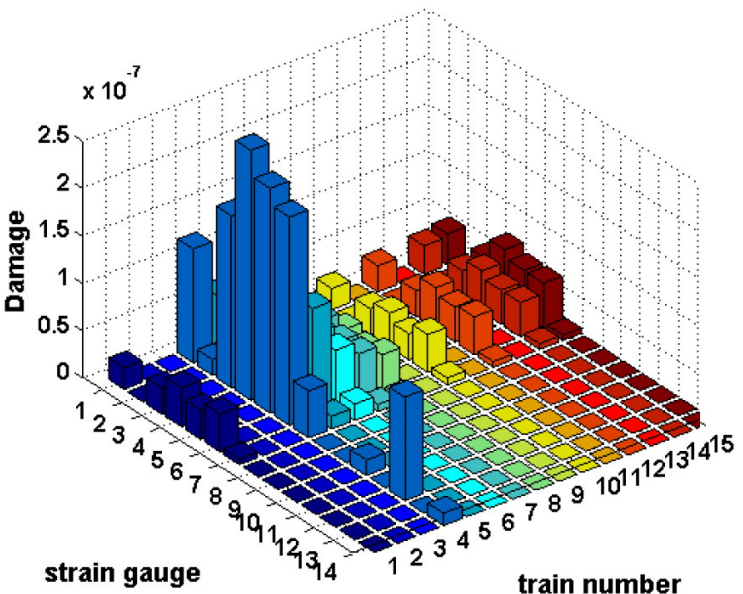

(a)
Damage per crossing (numerical)

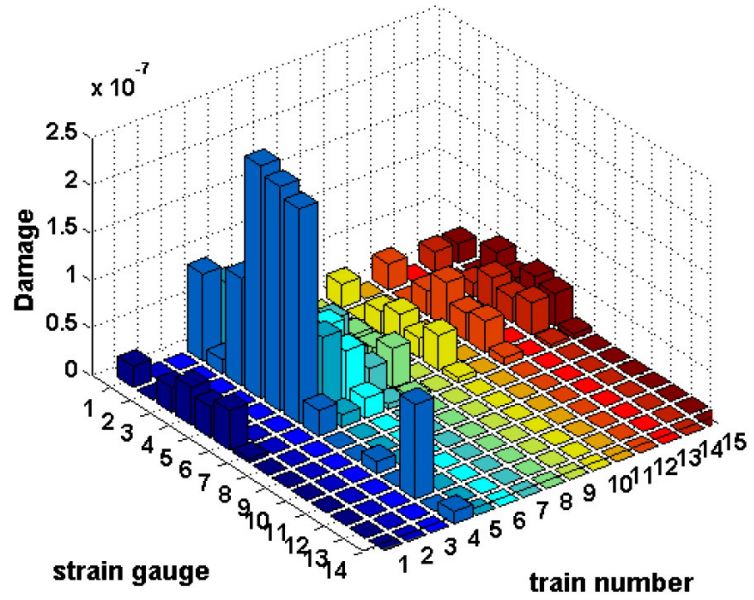

(b)

Fig. 26. Damage per crossing in measured sections for the 1st day of measurements: a) using measured stresses; b) using numerical simulations.

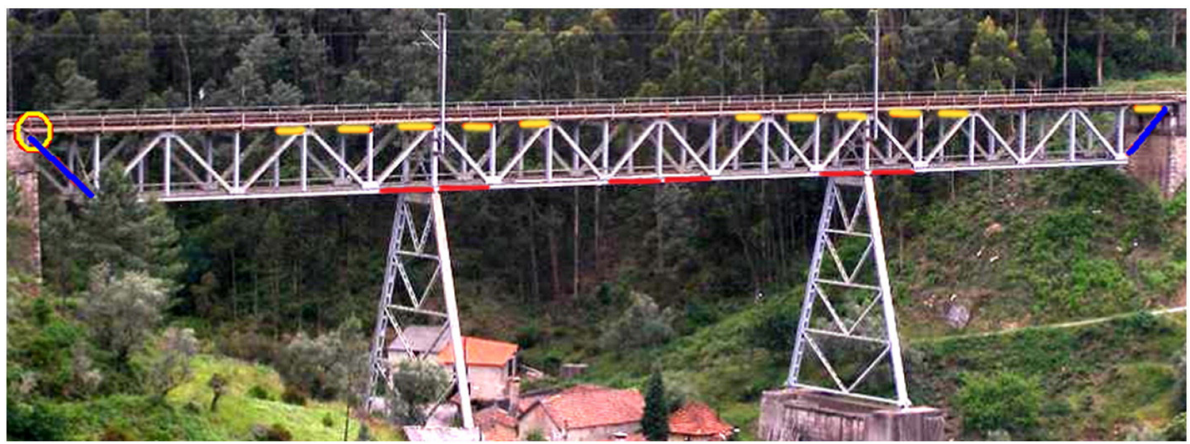

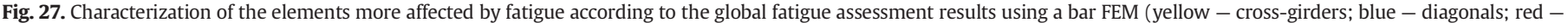
bottom chords). (For interpretation of the references to colour in this figure legend, the reader is referred to the web version of this article.)

stress spectra and with measured strains was reasonable. These results showed that for the bottom chord, it is possible to obtain a reasonable fatigue damage estimation using beam models and local shell models to calculate stress concentration factors. For the real traffic scenario the bridge has a fatigue damage below the failure limit. These damage indexes are much lower than the ones obtained from the simulations using the Eurocode trains.

- A detailed FEM with shell elements was further developed and validated using the results from the ambient vibration test and those from strain measurement campaigns. This more sophisticated model allowed the evaluation of geometry effects since all elements connected to the most stressed cross-girders were simulated with shell elements;

- The dynamic behaviour of the cross girders was subsequently analysed performing a field test campaign for preliminary identification of frequencies of local modes and a second measurement campaign with strain gauges in the cross-girders. The most relevant results provided by the application of the implemented routines to

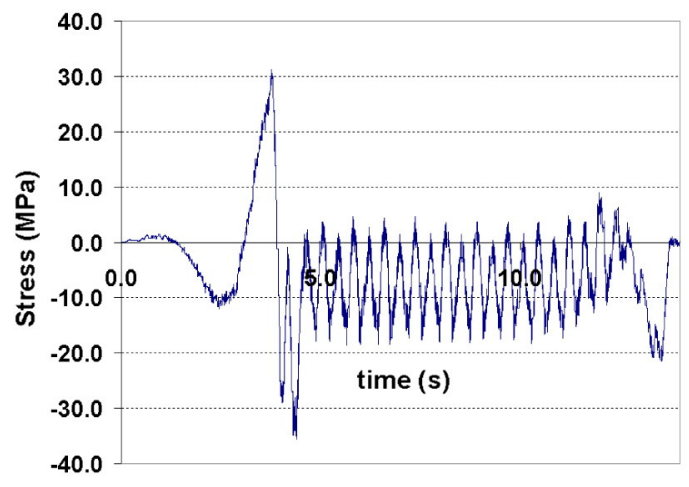

(a)

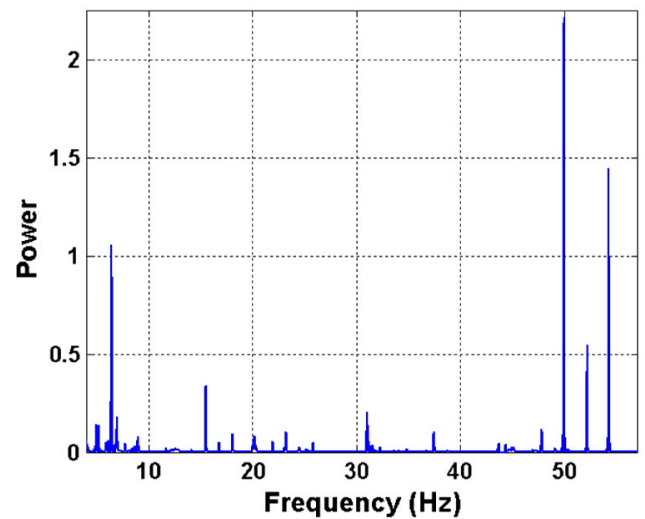

(b)

Fig. 28. Frequency analysis of a stress-time history: a) stress history at the cross girder above the column; b) frequency content of the signal. 


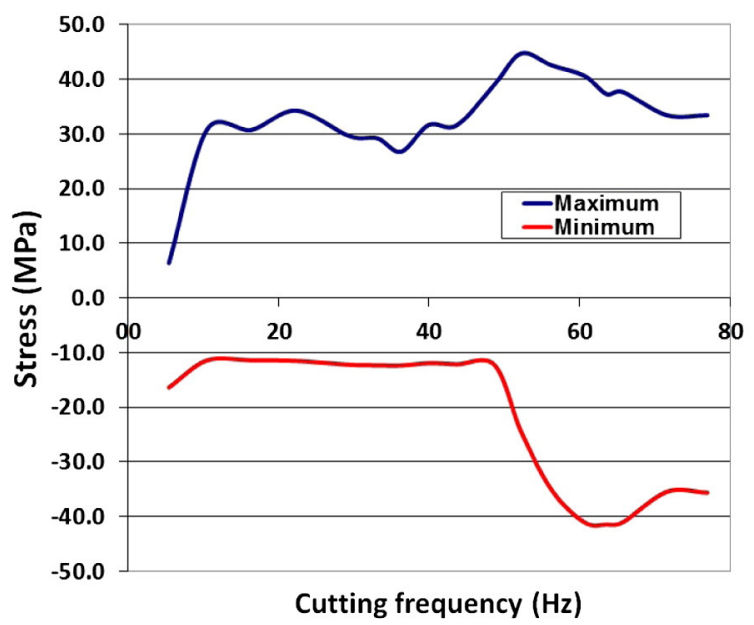

(a)

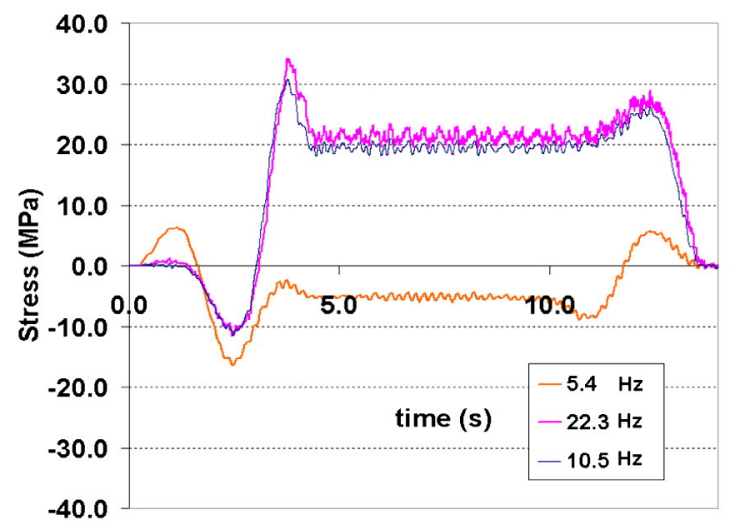

(c)

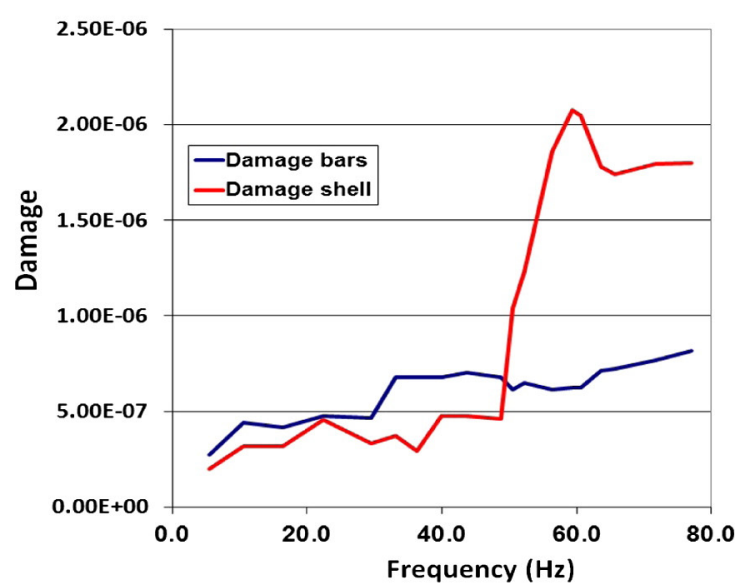

(b)

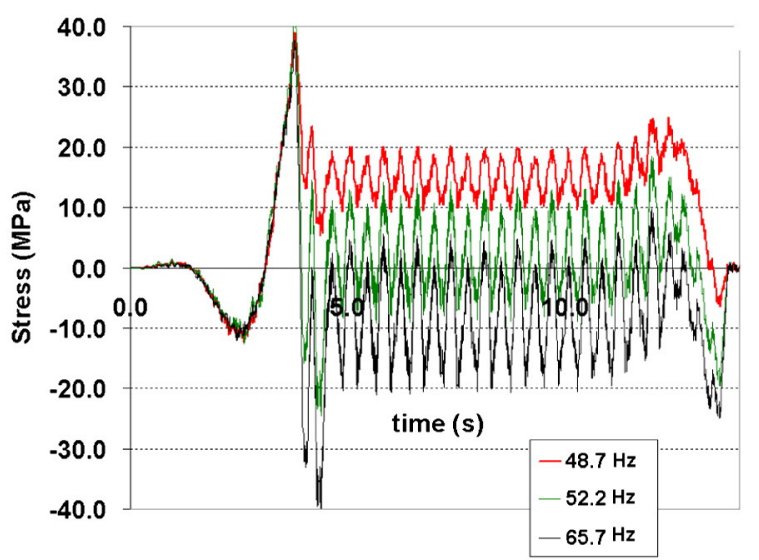

(d)

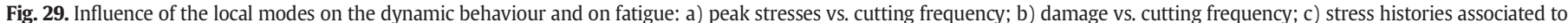
cutting frequencies of $5.4 \mathrm{~Hz} 10.5 \mathrm{~Hz}$ and $22.3 \mathrm{~Hz}$; d) stress histories associated to cutting frequencies of $48.7 \mathrm{~Hz}, 52.2 \mathrm{~Hz}$ and $65.7 \mathrm{~Hz}$.

the data collected during one year and five months of monitoring were presented. Numerical and estimated frequencies were correlated, which allowed to further increase the reliability of the local FEM. It was found that in order to evaluate correctly the dynamic behaviour and the fatigue damage of the cross-girders it was necessary to simulate them with shell elements because the beam FEM does not capture local modes with relevant contribution to the dynamic response;

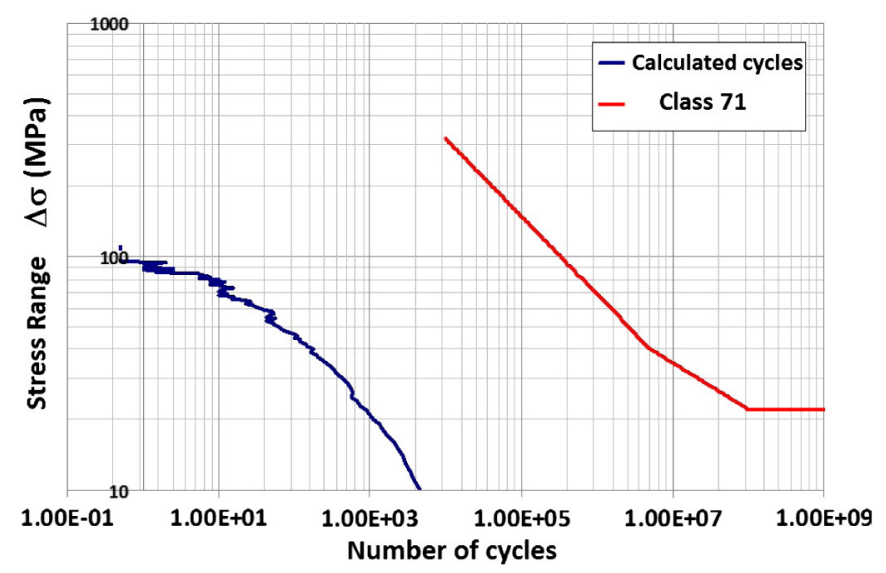

Fig. 30. Stress spectrum for strain gauge E6 and S-N curve for detail 71 of the EN1993-9 for a period of one year and five months.
- The local model and the strains measured in the cross-girders allowed a more accurate fatigue evaluation due to local vibration effects.

Some of the presented results are just related with a relatively short period of observation; the next months of operation of the continuous

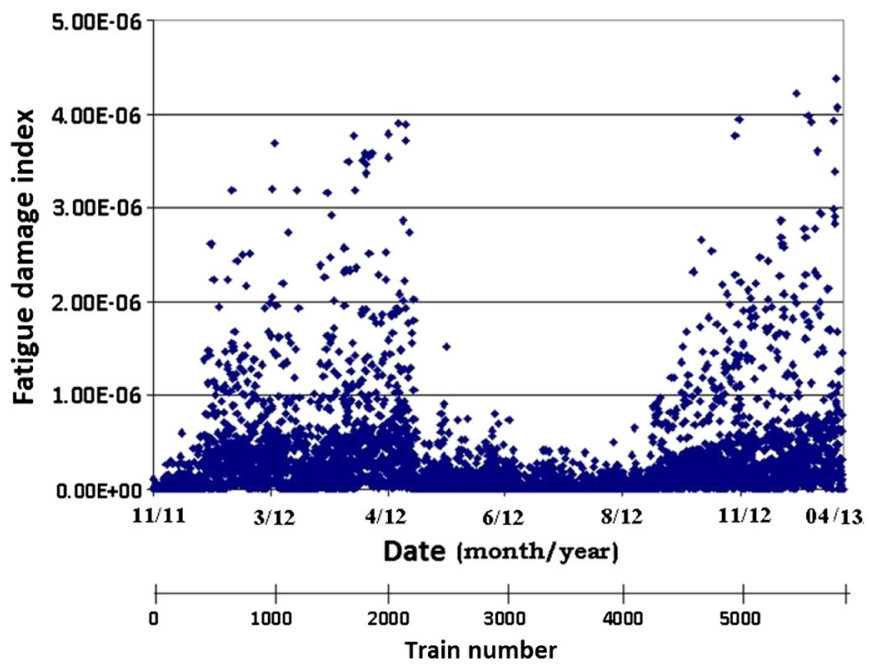

Fig. 31. Damage per crossing using measurements in strain gauge E6. 


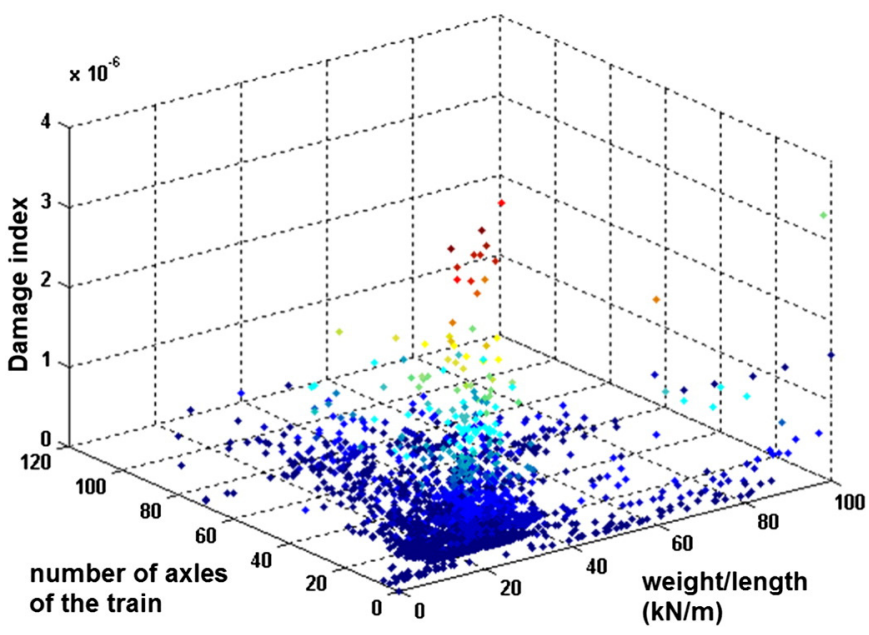

Fig. 32. Damage per crossing vs. number of axles vs. weight per length.

dynamic monitoring system will be useful to confirm the efficiency of the developed routines and to create a database for the traffic and for the estimation of fatigue in a long term perspective.

As future developments, the enhancement of the application of the WIM methodology and the analysis of a longer period of time are now under development. The corresponding new routines and calculations will provide clearer information about the traffic characteristics, the dynamic effects and fatigue behaviour of this bridge. Furthermore, more complex FEM taking into account the contact and friction and the inclusion of the rivets will be developed.

\section{Acknowledgements}

The authors would like to acknowledge: (1) all the supports provided by the Portuguese Foundation for Science and Technology (FCT) to ViBest/FEUP for the development of research in the area of Fatigue Assessment and Continuous Dynamic Monitoring; (2) the support of the Portuguese railway agency REFER and particularly of Eng. Ana Isabel Silva and Eng. José Carlos Clemente; (3) the Ph.D. Scholarship (SFRH/ $\mathrm{BD} / 75781 / 2011$ ) provided by FCT to the first author and (4) the financial support from the RFCS (Research Fund for Coal and Steel) (RFSR-CT2009-00027) in the context of the European Project Fatigue Damage Control and Assessment for Railway Bridges (FADLESS).

\section{References}

[1] Kühn B, Lukić M, Nussbaumer A, Günther H-P, Helmerich R, Herion S, et al. Assessment of existing steel structures: recommendation of remaining fatigue life. Technical Report under JRC - ECCS; February 2008.

[2] American Society of Civil Engineers (ASCE). Committee on fatigue and fracture reliability of the committee on structural safety and reliability of the structural division, fatigue reliability: 1-4. J Struct Eng ASCE 1982;108:3-88.

[3] Fisher JW. Fatigue and fracture in steel bridges: case studies. John Wiley; 1984.

[4] Fisher JW, Roy S. Fatigue of steel infrastructure. Proc. of Bridge Maintenance, Safety Management, Health Monitoring and Informatics IABMAS08 Conference; July 2008

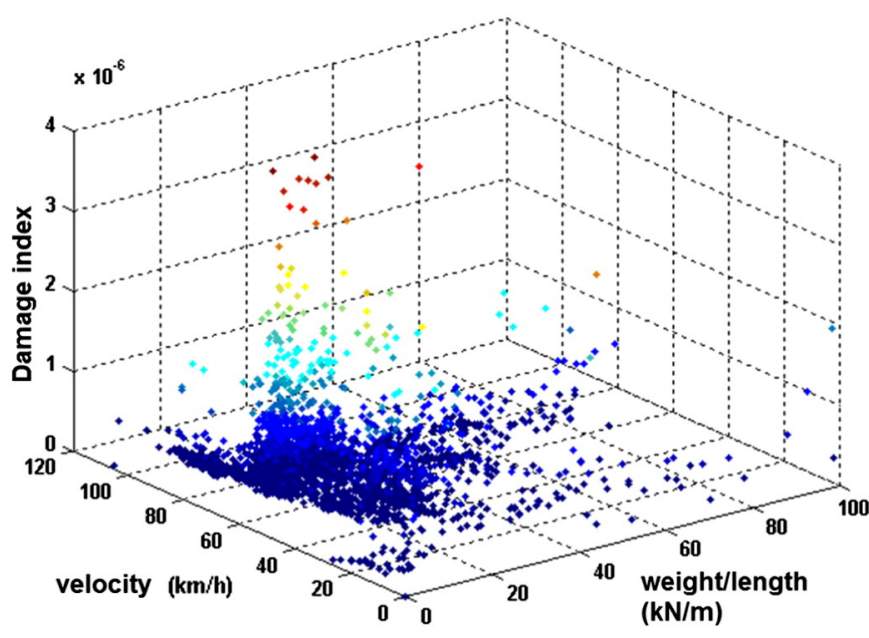

Fig. 33. Damage per crossing vs. velocity vs. weight per length.

[5] Guyer RC, Laman JA. Distortion-induced stress investigation of double angle stringer-to-floorbeam connections in railroad bridges. Eng Struct 2012;38:104-12.

[6] Cunha A, Caetano E, Magalhães F, Moutinho C. Recent perspectives in dynamic testing and monitoring of bridges. J Struct Control Health Monit 2012;20(6):853-77. http://dx.doi.org/10.1002/stc.1516.

[7] Magalhães F, Cunha A, Caetano E. Vibration based structural health monitoring of an arch bridge: from automated OMA to damage detection. Mech Syst Signal Process 2012;28:212-28.

[8] Leander J, Andersson A, Karoumi R. Monitoring and enhanced fatigue evaluation of a steel railway bridge. Eng Struct 2010;32:854-63.

[9] SOLVIA. Finite element system. http://www.solvia.com/.

[10] Bathe K. A solution method for planar and axisymetric contact problems. Int J Numer Methods Eng 1985:21:65-88.

[11] Cunha Á, Caetano E, Magalhães F. Output-only dynamic testing of bridges and special structures. Struct Concr June 2007:8(2):67-85.

[12] Magalhães F, Cunha A. Explaining operational modal analysis with data from an arch bridge (Review). Mech Syst Signal Process July 2011;25(5):1431-50.

[13] Peeters B, El-Kafafy M, Guillaume P. Dealing with uncertainty in advanced frequency-domain operational modal analysis. CST2012, Eleventh International Conference on Computational Structures Technology; 2012.

[14] ANSYS simulation software. Finite element system. http://www.ansys.com/.

[15] Moses F. Weigh-in-motion system using instrumented bridges. Transp Eng J ASCE 1979;105:233-49.

[16] Liljencrantz A, Karoumi R, Olofsson P. Implementing bridge weigh-in-motion for railway traffic. Comput Struct 2007;85:80-8.

[17] Project co-ordinator: Norwegian Geotechnical Institute (NGI). Sustained Performance of Railway Tracks (SUPERTRACK). Final Report; 2005.

[18] CEN European Committee for Standarsization; 2003.

[19] CEN European Committee for Standarsization. Eurocode 3: design of steel structures part 1.9: fatigue strength of steel structures; EN 1993-1-9; 2002.

[20] Taras A, Greiner R. Development and application of a fatigue class catalogue for riveted bridge components. Struct Eng Int 2010;20(13):91-103.

[21] Matsuishi M, Endo T. Fatigue of metals subjected to varying stress. Jpn Soc Mech Eng 1968.

[22] Downing SD, Socie DF. Simple rainflow counting algorithms. Int J Fatigue January 1982;4(1):31-40.

[23] Ribeiro A, Figueiredo M, Jesus A, Castro P, Fernandes A. Avaliação da integridade estrutural da ponte de Trezói. Report for the portuguese national research project “Avaliação da Integridade Estrutural de Pontes Metálicas Ferroviárias"; 2004.

[24] Goodman J. Mechanics applied to engineering. London: Longmans, Green and Co.; 1919 631-6. 